PAMELA SILVESTRE BACKSCHAT

"AVALIAÇÃO DOS PARÂMETROS HEMATOLÓGICOS E BIOQUÍMICOS DE CÃES ADULTOS DA RAÇA DACHSHUND"

SÃO PAULO

2017 


\section{"AVALIAÇÃO DOS PARÂMETROS HEMATOLÓGICOS E BIOQUÍMICOS DE CÃES ADULTOS DA RAÇA DACHSHUND”}

Dissertação apresentada ao Programa de PósGraduação em Clínica Veterinária da Faculdade de Medicina Veterinária e Zootecnia da Universidade de São Paulo para a obtenção do título de Mestre em Ciências

Departamento:

Clínica Médica

Área de concentração:

Clínica Veterinária

Orientador:

Prof ${ }^{a}$. Drª . Maria Helena Matiko Akao Larsson

São Paulo 
Autorizo a reprodução parcial ou total desta obra, para fins acadêmicos, desde que citada a fonte.

DADOS INTERNACIONAIS DE CATALOGAÇÃO NA PUBLICAÇÃO

(Biblioteca Virginie Buff D’Ápice da Faculdade de Medicina Veterinária e Zootecnia da Universidade de São Paulo)

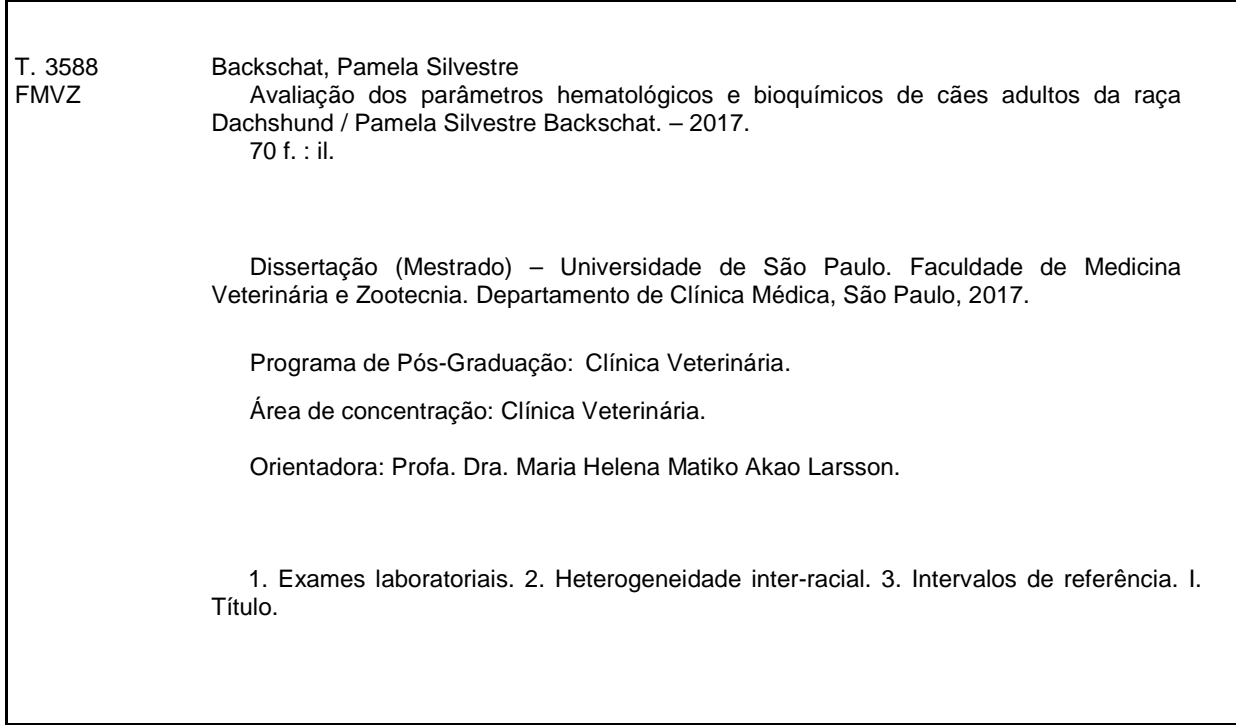

Ficha catalográfica elaborada pela bibliotecária Camila Molgara Gamba, CRB 7070-8, da FMVZ/USP. 
UNIVERSIDADE DE SÃo PAULO

IImo(a). Sr(a).

Responsável: Maria Helena Matiko Akao Larsson

Area: Cardiologia

Profa. Dra. Maria Helena Matiko Akao Larsson (orientador)

Título da proposta: "PADRONIZAÇÄO DE PARÃMETROS ECOCARDIOGRÁFICOS, ELETROCARDIOGRÁFICOS, RADIOGRÁFICOS, LABORATORIAIS E PRESSÄO ARTERIAL SISTOLLICA PELO MÉTODO DOPPLER EM CÄES DA RAÇA DACHSHUND".

\section{Parecer Consubstanciado da Comissão de Ética no Uso de Animais FMVZ/USP}

A Comissão de Ética no Uso de Animais da Faculdade de Medicina Veterinária e Zootecnia da Universidade de São Paulo, no cumprimento das suas atribuiçōes, analisou e APROVOU a Notificaçăo (versāo de 26/março/2017) da proposta acima referenciada.

Resumo apresentado pelo pesquisador: "Em anexo segue notificação de uso do TCLE do presente projeto para o projeto intitulado "Avaliação dos parâmetros hematológicos e bioquímicos de cães adultos da raça Dachshund" "

Comentário da CEUA: "Documento aprovado.".

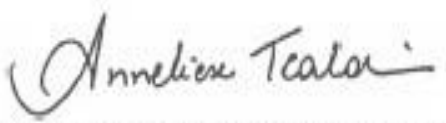

Profa. Dra. Anneliese de Souza Traldi Presidente da Comissão de Ética no Uso de Animais Faculdade de Medicina Veterinária e Zootecnia da Universidade de São Paulo

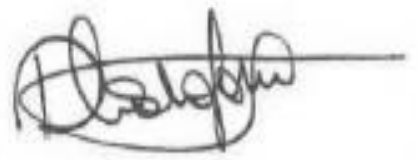

Roseli da Costa Gomes Secretaria Executiva da Comissão de Ética no Uso de Animais Faculdade de Medicina Veterinária e Zootecnia da Universidade de Săo Paulo 
FOLHA DE AVALIAÇÃO

Autor: BACKSCHAT, Pamela Silvestre

Título: Avaliação dos parâmetros hematológicos e bioquímicos de cães adultos da raça Dachshund

Dissertação apresentada ao Programa de Pós-Graduação em Clínica Veterinária da Faculdade de Medicina Veterinária e Zootecnia da Universidade de São Paulo para obtenção do titulo de Mestre em Ciências

Data:

1

\section{Banca Examinadora}

Prof. Dr.

Instituição: Julgamento:

Prof. Dr. Instituição: Julgamento:

Prof. Dr. Instituição: Julgamento: 


\section{DEDICATÓRIA}

\section{À minha família:}

Aos meus pais, Maria e Almir, a minha mãe que sempre esteve comigo nos melhores e, principalmente, nos piores momentos e por ser meu suporte principal nessa vida, a meu pai que possibilitou a realização do sonho da medicina veterinária, meu herói, meu exemplo.

Ao meu irmão, Fernando pela companhia e desabafos ao longo de todo esse tempo que me permitiram continuar mesmo diante do momento mais difícil da minha vida.

Ao meu irmão Felipe, que mesmo na ausência, se permitiu presente e por me abençoar com a luz da minha vida,meu sobrinho Murillo.

À professora Maria Helena Matiko Akao Larsson que tornou tudo isso realidade. Meu ídolo na cardiologia e medicina veterinária, uma honra inestimável poder fazer parte da história dessa grande profissional.

Aos residentes e alunos de graduação que estiveram presentes na minha rotina e que exercitaram meu lado científico dia a dia.

Aos colegas de Pet Care, que sem o auxílio deles, o sonho do mestrado não seria concluído. 


\section{AGRADECIMENTOS}

Agradeço a minha professora e orientadora Maria Helena Matiko Akao Larsson, por toda confiança e pela oportunidade de fazer parte de sua história, uma honra e um sonho que somente pude realizar pelo espaço cedido por esta grande e maravilhosa profissional, pela qual tenho imenso carinho e admiração.

Às minhas amigas de pós-graduação, Bruna Padin e Cinthia Keiko Souto, que se mantiveram presentes nos momentos cruciais, sempre me apoiando e me ajudando nas melhores decisões a tomar. E como a Cinthia sempre me disse, um mestrado não se faz sozinha.

À médica veterinária Andrea Ferreira, minha melhor amiga e preceptora por todos conselhos e companhia.

Agradeço a minha prima Daniela Silvestre Zonatto e cunhada Vani Santos pelas horas de desabafo e carinho por todo esse tempo.

Á minha amiga Rafaela Issa que além de me dispor sua amizade também me serviu de exemplo de dedicação e determinação.

Aos Serviços de Cardiologia, Laboratório Clínico e de Imagem da FMVZ-USP que possibilitaram a realização desse projeto, e um agradecimento em especial aos colegas: Paula Hiromi Itikawa, pelo projeto realizado concomitantemente; Sarah Oliveira, pela companhia e ajuda nas tabulações dos dados; Hugo e Reginaldo, pela ajuda matutina na realização das radiografias torácicas; Diego Modena, Daphnis Oliveira.

Aos professores do serviços que possibilitaram a realização desse projeto: Profa Dra Carla Lorigrado, Profa Dra Ana Carolina Brandão, Prof Dr. Stefano Hagen; Profa Dra Márcia Mery Kogika. 
Á Profa Dra. Maria Claudia Sucupira pelas intruções e conselhos dados nesses dois anos de mestrado.

Ao Pet Care, principalmente às unidades Tatuapé e Pacaembu, representadas pelos colegas: Maiara Leme, Viviane Azevedo, Cléber Fontana e Sibele Konno, chefes das unidades que mantiveram a paciência e toda confiança nas trocas de escala para que eu pudesse realizar as disciplinas e coleta de dados na rotina, bem como a todos os colegas que trocaram de horário e me incentivaram nessa jornada. Sinto um imenso orgulho em estar ao lado de vocês.

Ao meu amigo, orientador do curso de Especialização em Cardiologia Veterinária, André Martins Gimenes, que acreditou em mim desde o início da minha residência e que também me auxiliou na confecção da estatística desse trabalho.

À analista Ana Carolina Diaz, por estes três anos de análise que me fizeram chegar até aqui, me mantendo convicta no caminho que escolhi e afastando as dúvidas que a vida me impôs.

Aos residentes, alunos de graduação e de especialização em Cardiologia Veterinária que foram companheiros diários na luta pelo conhecimento e saber, os quais instigaram meu lado científico e fizeram com que a realização do mestrado aumentasse seu sentido.

Agradeço ao Guilherme Pereira e Ronaldo Jun pela companhia e ensinamentos desde o momento que os conheci até os dias de hoje.

Aos animais e proprietários que aceitaram participar do projeto e fizeram desse projeto possível.

Por fim, agradeço aos meus animais de estimação, Sakura, Winlly, Agome, Saori, Keiko, Link, Midna, Hiei, Haido, Marie e Diego, pela inspiração desde o início 
do sonho da medicina veterinária que me mantiveram firme e me deram a alegria de viver, e a todos os animais que tive a oportunidade cuidar até então. 


\section{RESUMO}

BACKSCHAT, P. S. Avaliação dos parâmetros hematológicos e bioquímicos de cães adultos da raça Dachshund. [Evaluation of hematological and biochemical parameters of Dachshund adult dogs]. 2017. 70 f. Dissertação (Mestrado em Ciências) - Faculdade de Medicina Veterinária e Zootecnia, Universidade de São Paulo, São Paulo, 2017.

A espécie canina foi descrita como a espécie mais polimórfica do planeta, apresentando vasta heterogeneidade interracial, mas perceptível homogeneidade intrarracial. Em considerando tal informação, a necessidade de pesquisas para constatar tais divergências, principalmente no que se diz respeito ao intervalo de referência de exames laboratoriais, vem se expandindo de maneira exponencial, com intuito de afastar qualquer interpretação equivocada e complementar no diagnóstico clínico. Portanto, a hipótese foi que de cães da raça Dachshund apresentam parâmetros hematológicos e bioquímicos diversos daqueles referenciados, na literatura, para a espécie canina. Assim, o objetivo foi determinar os parâmetros hematológicos e bioquímicos de cães adultos e sadios da raça Dachshund e compará-los aos já existentes (valores de referência) na literatura para a espécie em questão. Avaliaram-se 69 animais adultos e sadios da raça Dachshund, referentes a 23 parâmetros laboratoriais, quais sejam: contagem total de hemácias $(\mathrm{He})$, hemoglobina $(\mathrm{Hb})$, hematócrito $(\mathrm{Ht})$, volume corpuscular médio (VCM), concentração de hemoglobina corpuscular média ( $\mathrm{CHCM}$ ), hemoglobina corpuscular média (HCM), contagem total de leucócitos, neutrófilos totais, metamielócitos, bastonetes, segmentados, linfócitos típicos, linfócitos atípicos, monócitos, eosinófilos, basófilos, plaquetas, proteína total, albumina, alanina aminotransferase (ALT), fosfatase alcalina (FA), ureia e cretinina. Após análise estatística, concluiu-se que os analitos hematócrito, hemoglobina e albumina apresentaram valores maiores quando comparados com os intervalos de referência já existentes, corroborando, assim, a heterogeneidade interracial existente e a necessidade do conhecimento de tais diferenças na rotina clínica.

Palavras-chave: Exames laboratoriais. Heterogeneidade inter-racial. Intervalos de referência. 
ABSTRACT

BACKSCHAT, P. S. Evaluation of hematological and biochemical parameters of Dachshund adult dogs. [Avaliação dos parâmetros hematológicos e bioquímicos de cães adultos da raça Dachshund]. 2017. 70 f. Dissertação (Mestrado em Ciências) - Faculdade de Medicina Veterinária e Zootecnia, Universidade de São Paulo, São Paulo,2017.

The canine species was described as the most polymorphic species on the planet, presenting vast inter-racial heterogeneity, but noticeable intrarracial homogeneity. Taking this information into account, the need for research to verify such divergences, especially regarding the reference interval of laboratory exams, has been expanding exponentially, in order to avoid any misinterpretation and complementary interpretation in the clinical diagnosis. Therefore, the hypothesis was that of Dachshund dogs have hematological and biochemical parameters different from those referenced in the literature for the canine species. Thus, the objective was to finish the hematological and biochemical parameters of adult and healthy dogs of the Dachshund breed and to compare them with the existing ones (reference values) in the literature for the species in question. A total of 69 healthy adult Dachshund animals were evaluated objectifying 23 laboratory parameters: red blood cell count $(\mathrm{Hb})$, hemoglobin $(\mathrm{Hb})$, hematocrit $(\mathrm{Ht})$, mean corpuscular volume (MCV), corpuscular hemoglobin concentration (total cholesterol), total neutrophils, metamielocytes, segmented rods, typical lymphocytes, atypical lymphocytes, monocytes, eosinophils, basophils, platelets, total protein, albumin, alanine aminotransferase (ALT), total corpuscular hemoglobin (HCMM) , alkaline phosphatase (FA), urea and creatinine. After statistical analysis, it was concluded that hematocrit, hemoglobin and albumin analytes presented higher values when purchased with the existing reference intervals, thus corroborating the interracial heterogeneity and the need for knowledge of such differences in clinical routine.

Key-words: Laboratory tests. Interracial heterogeneity. Intervals of reference. 


\section{LISTA DE FIGURAS}

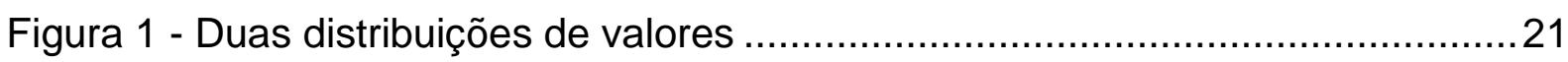

Figura 2 - Composição sanguínea aproximada de um cão normal ......................... 26 


\section{LISTA DE TABELAS}

Tabela 1 - Critérios para seleção e exclusão de indivíduos de referência

Tabela 2 - Procedimentos recomendados para estabelecimento do intervalo de referência baseado no tamanho da amostra e distribuição

Tabela 3 - Fatores pré-analíticos para consideração e padronização com base no conhecimento prévio do analito e seus efeitos sobre a qualidade e os resultados das amostras

Tabela 4 - Valores dos parâmetros do eritrograma de cães adultos da raça

Dachshund

Tabela 5 - Valores dos parâmetros do leucograma de cães adultos da raça Dachshund

Tabela 6 - Valores dos parâmetros de função hepática e renal de cães adultos da raça Dachshund

Tabela 7 - Valores hematológicos e bioquímicos de cães adultos e sadios da raça Dachshund e intervalo de referência do Serviço de Laboratório Clínico, VCM-HOVET-FMVZ-USP 


\section{LISTA DE GRÁFICOS}

Gráfico 1 - Fluxograma dos animais atendidos no Serviço de Cardiologia do HOVETUSP

Gráfico 2 - Histogramas das distribuições de valores obtidos das análises hematológicas e bioquímicas de cães adultos da raça Dachshund 40

Gráfico 3 - Representação gráfica no formato boxplot do grupo idade com relevânci estatística $(p<0,05)$ de cães adultos da raça Dachshund 


\section{LISTA DE ABREVIATURAS}

$\begin{array}{ll}\text { ALT } & \text { Alanina aminotransferase } \\ \text { AST } & \text { Aspartato aminotransferase } \\ \text { CHCM } & \text { Concentração de hemoglobina corpuscular média } \\ \text { CK } & \text { Creatinaquinase } \\ \text { FA } & \text { Fosfatase alcalina } \\ \text { FMVZ } & \text { Faculdade de Medicina Veterinária e Zootecnia } \\ \text { GGT } & \text { Gamaglutamiltransferase } \\ \text { Hb } & \text { Hemoglobina } \\ \text { HCM } & \text { Hemoglobina corpuscular média } \\ \text { He } & \text { Hemácia } \\ \text { HOVET } & \text { Hospital Veterinário } \\ \text { Ht } & \text { Hematócrito } \\ \text { IVCM } & \text { Insuficiência valvar crônica de mitral } \\ \text { PAS } & \text { Pressão arterial sistólica } \\ \text { Pt } & \text { Proteína total } \\ \text { RPM } & \text { Rotação por minuto } \\ \text { USP } & \text { Universidade de São Paulo } \\ \text { VCM } & \text { Departamento de Clínica Médica }\end{array}$




\section{SUMÁRIO}

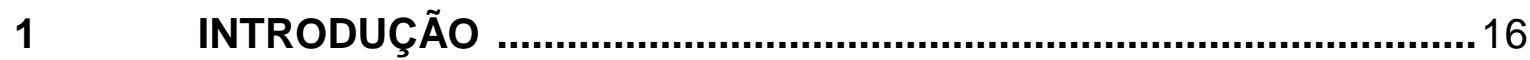

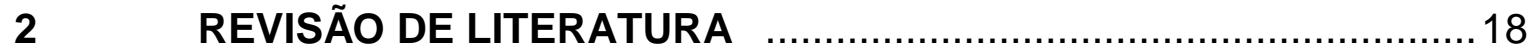

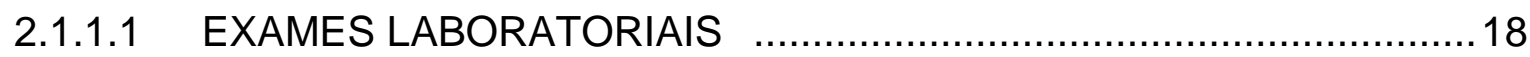

2.1.1.2 Intervalos de referência …...................................................... 18

2.1.1.3 Procedimentos pré-analíticos, analíticos e pós-analíticos do

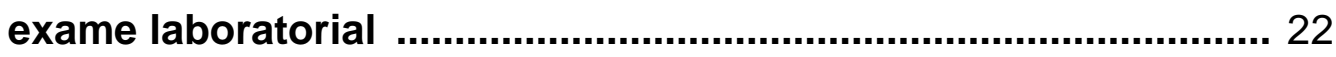

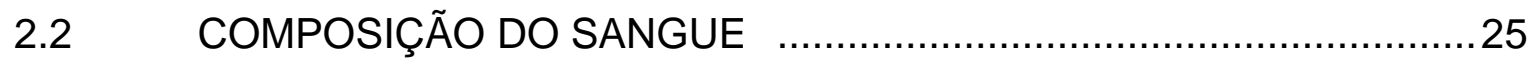

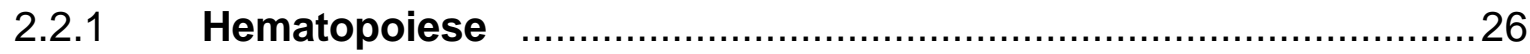

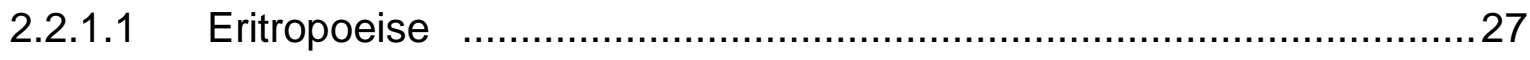

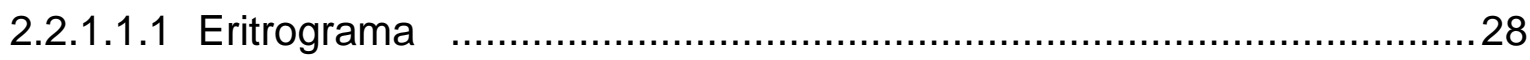

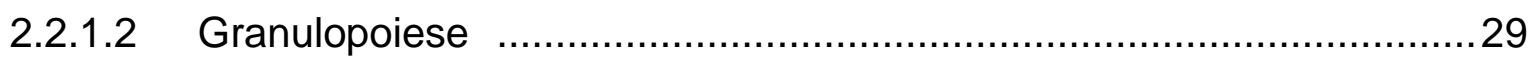

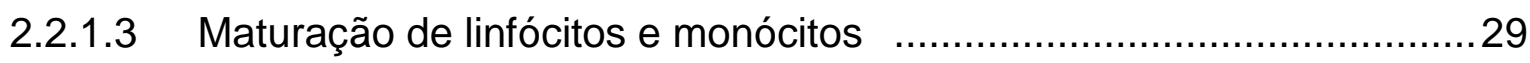

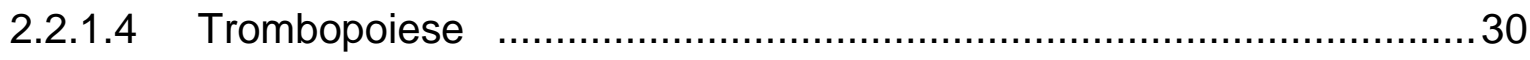

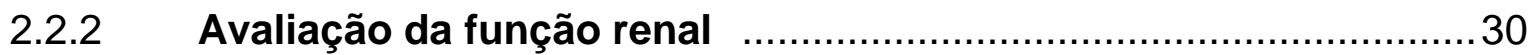

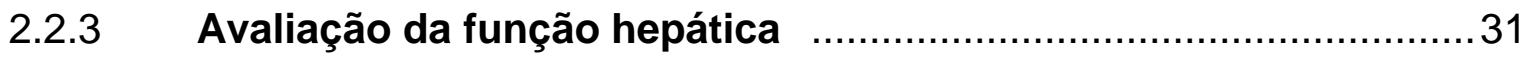

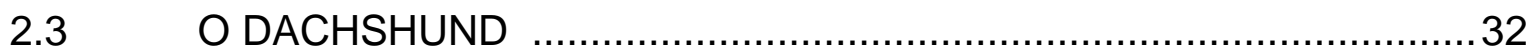

2.3.1 A variabilidade racial e os exames laboratorias …........................33

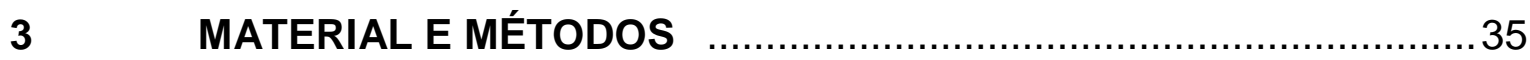

3.1 COMISSÃO DE ÉTICA NO USO DE ANIMAIS .................................. 35

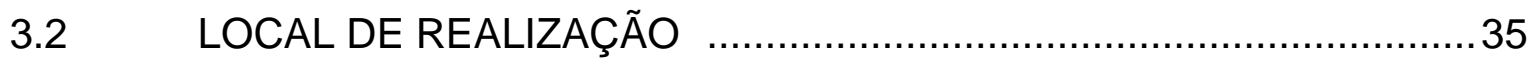

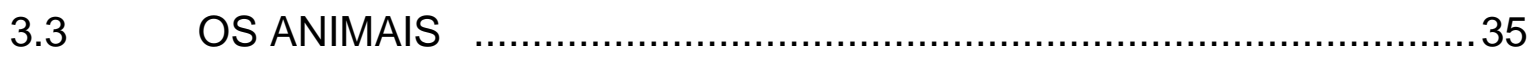

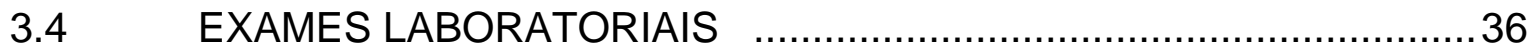

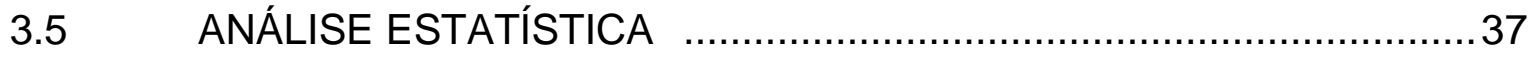

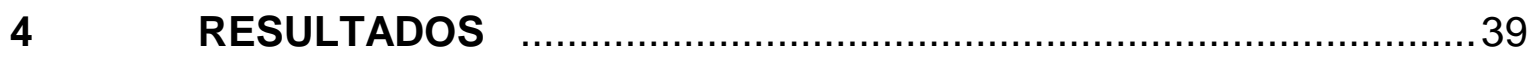

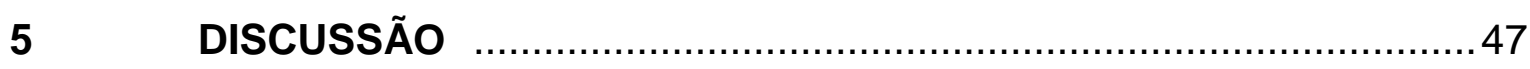

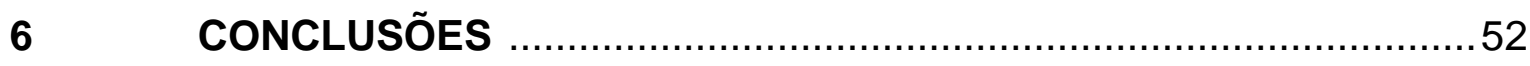

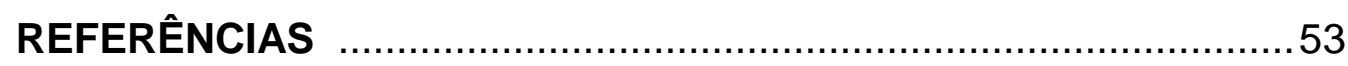

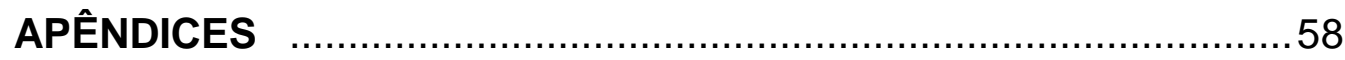




\section{INTRODUÇÃO}

Os exames laboratoriais, entre eles o hemograma e a bioquímica sérica, permitem ao clínico uma melhor abordagem e entendimento do caso e, até mesmo, direcionam uma melhor medida a ser tomada diante de uma decisão terapêutica. Embora conhecidos e estudados há muito tempo, os valores de referência sofrem interferência de fatores externos, como o ambiente em que se vive, época do ano, estilo de vida e até mesmo da dieta (RAUTENBACH et al., 1987; RAUTENBACH ; JOUBERT, 1988; NIELSEN et al., 2010). Não somente fatores externos, mas outros como idade, sexo, raça e esterilização também já foram avaliados em relação aos valores de referência em determinadas raças (HARPER et al., 2010; NIELSEN et al., 2010; LAWRENCE et al., 2013).

Em 1971, Porter e Canaday realizaram um estudo comparativo dos valores hematológicos entre cães sem definição racial e os da raça Greyhound e o resultado foi que houve diferença entre os dois grupos estudados. Este e outros estudos demonstraram a grande variabilidade de valores de referência entre as diferentes raças.

Estudos de padronização de valores hematológicos já foram realizados e observaram-se particularidades raciais em condições fisiológicas. Campora et al. (2011) observaram altos valores referentes ao eritrograma (contagem global de hemácias, hemoglobina e hematócrito) e baixos valores relacionados à contagem global de leucócitos e plaquetas em cães da raça Greyhound, corroborando com estudos anteriores (SULLIVAN et al., 1994; SHIEL et al., 2007).

Nielsen et al. (2010) realizaram estudo com cães adultos e sadios da raça Bernese Mountain, comparando os valores hematológicos e bioquímicos com valores de referências já pré-estabelecidos para a espécie. Concluíram que sete valores hematológicos e bioquímicos, entre eles eosinófilos, concentração de hemoglobina corpuscular média, fosfatase alcalina, gama-glutamiltransferase, bilirrubina total, amilase e colesterol apresentaram diferença significativa, evidenciando a importância da variação racial e a relevância clínica no momento da interpretação laboratorial no auxílio do diagnóstico.

Ao comparar quatro raças (Malamute do Alaska, Husky Siberiano, Golden Retriever e Setter Inglês) em relação à bioquímica sérica, Sharkey et al. (2009) 
constataram diferença estatística entre elas, no entanto, a diferença observada foi pequena e sem relevância clínica.

Cães da raça Dachshund apresentam acondroplasia/hipocondroplasia considerada uma condição fisiológica. $\mathrm{Na}$ medicina humana, a acondroplasia/hipocondroplasia afeta o osso endocondral induzindo o indivíduo a apresentar nanismo desproporcional, microcefalia, hipoplasia facial e alterações em coluna vertebral (GOUGH ; THOMAS, 2010). Na idade média, os Dachshunds descenderam de cães da raça Braco, com o intuito de realizar caça subterrânea e, dessa forma, evoluíram para padrão racial de patas curtas, versáteis para caça. Apresentam corpo longo com membros curtos, arqueados e musculosos (Enciclopédia do Cão, 2001), esterno largo e proeminente com a caixa torácica oval e ampla, com coração e pulmões bem desenvolvidos (Confederação Brasileira De Cinofilia, 2015 - http://www.cbkc.com.br/padroes/pdf/grupo4/dachshund.pdf; consulta em 10 de Maio de 2016). Tal conformação corpórea proporciona à raça uma maior dificuldade e particularidades para realização de exames dentro de uma rotina clínica, conferindo a necessidade de padronização dos intervalos de normalidade segundo diversos meios de avaliação clínica.

Em 2015, a raça Dachshund foi comparada com cães sem definição racial em relação aos valores hematológicos, concluindo-se que cães desta raça apresentam valores maiores de hematócrito, eritrócitos e hemoglobina (TORRES et al., 2015).

A hipótese do presente trabalho foi de que por haver variação hematológica e bioquímica nas diferentes raças já estudadas, os Dachshunds também poderiam apresentar valores de referência diferentes dos já estabelecidos para a espécie canina de modo geral.

Assim sendo, os objetivos foram: determinar os parâmetros hematológicos e bioquímicos de cães adultos e sadios da raça Dachshund e compará-los aos já existentes (valores de referência) na literatura para a espécie canina.

Consciente da grande variação de raças caninas no tocante aos parâmetros hematológicos e bioquímicos, entre outros, bem como da importância de valores de referência desses parâmetros na condução e estabelecimento de diagnóstico clínico, justifica-se a necessidade do conhecimento dos mesmos para a raça Dachshund. 


\section{REVISÃO LITERATURA}

\subsection{EXAMES LABORATORIAIS}

$\mathrm{Na}$ rotina clínica, os exames laboratoriais devem ser utilizados juntamente com outros procedimentos diagnósticos, a exemplo da obtenção de um histórico detalhado, ou anamnese, bem como a realização de um exame físico completo. Assim, a partir desses procedimentos, o clínico pode selecionar exames laboratoriais para esclarecer ou classificar problemas identificados (STOCKHAM ; SCOTT, 2011).

Os exames laboratoriais foram desenvolvidos para detectar ou quantificar substâncias ou células em amostras de sangue, urina e outras amostras de fluidos corpóreos, e tal substância ou célula de interesse é chamada de analito (WEISER, 2006; STOCKHAM ; SCOTT, 2011).

Os testes hematológicos são, na maioria, realizados com amostras de sangue total para quantificar a concentração de células sanguíneas, como contagem de leucócitos totais, contagem de eritrócitos e contagem de plaquetas. Nessas amostras de sangue, também é possível definir e classificar as células de acordo com sua característica microscópica e, até mesmo, aferir as propriedades coagulantes do sangue, como tempos de coagulação e testes de função plaquetária (WEISER, 2006; HARVEY, 2012).

Por outro lado, os testes bioquímicos são, em sua maioria, realizados em amostras de soro ou plasma, onde é possível detectar e/ou quantificar concentrações de uma substância química, a exemplo da concentração sérica de sódio, proteínas, creatinina e ureia, entre outras (STOCKHAM ; SCOTT, 2011).

\subsubsection{Intervalos de referência}

Para o reconhecimento dos resultados de exames laboratoriais serem considerados normais, os valores de referência de animais saudáveis necessitam de avaliação. Esses valores são comumente nomeados como intervalos de referência ou valores normais (LASSEN, 2006; STOCKHAM ; SCOTT, 2011). Tal conceito de intervalo de referência foi instituído na medicina humana em 1969 e, a partir daí, disseminada para a medicina veterinária (GRÄSBECK ; SARIS, 1969; FRIEDRICHS et al., 2012). 
Os valores de referência compreendem $95 \%$ da população determinada saudável e a partir daí tornam-se intervalos de referência para tomada de decisão em uma rotina clínica (FRIEDRICHS et al., 2012). Para a seleção de tais indivíduos, deve-se trabalhar com critérios de seleção como: fatores biológicos, clínicos e geográficos (Tabela 1). Os procedimentos para verificação de salubridade devem ser minuciosamente definidos, assim como os critérios de exclusão utilizados (LASSEN, 2006; FRIEDRICHS et al.,2012).

Tabela 1. Critérios para seleção e exclusão de indivíduos de referência

\begin{tabular}{|c|c|c|}
\hline Classificação & Categoria & Exemplo \\
\hline \multicolumn{3}{|l|}{${ }^{*}$ Critério de seleção } \\
\hline \multirow[t]{4}{*}{ Biológica } & Idade & Neonato, jovem, adulto \\
\hline & Sexo & Fêmea, macho \\
\hline & Raça & Holstein, Angus \\
\hline & Procedência & $\begin{array}{l}\text { Macacos de Maurício ou } \\
\text { Sudeste da Ásia }\end{array}$ \\
\hline \multirow[t]{5}{*}{ Clínica } & Histórico & $\begin{array}{l}\text { Nenhum sintoma de doença } \\
\text { dentro de } 2 \text { semanas que } \\
\text { precedem a coleta da amostra }\end{array}$ \\
\hline & Tratamentos preventivos & Vacinação, vermifugação \\
\hline & Salubridade & Exame físico \\
\hline & Avaliação diagnóstica & $\begin{array}{l}\text { Hematologia, Bioquímico, } \\
\text { urinálise, exames de imagem }\end{array}$ \\
\hline & Tipo de criação & $\begin{array}{c}\text { Domiciliado, fazendo, vida livre, } \\
\text { dieta }\end{array}$ \\
\hline \multirow[t]{2}{*}{ Geográfico } & Localização & $\begin{array}{c}\text { Costeira, montanhas, } \\
\text { temperatura, estado e região } \\
\text { específica }\end{array}$ \\
\hline & Ambiente & Temperatura ambiental \\
\hline \multicolumn{3}{|c|}{${ }^{*}$ Critérios de exclusão } \\
\hline \multirow[t]{2}{*}{ Biológico } & Metabólico & $\begin{array}{c}\text { Com ou sem jejum, exercício } \\
\text { intenso, estresse }\end{array}$ \\
\hline & Dano celular & Punção venosa traumática \\
\hline Fisiológica & & Medicações, lactação, prenhez \\
\hline Medicamentos & & $\begin{array}{c}\text { Hormônios, indutores } \\
\text { enzimáticos (corticoides ou } \\
\text { antiepiléticos) }\end{array}$ \\
\hline
\end{tabular}

Fonte: FRIEDRICHS et al., 2012.

No geral, quanto maior o número de amostras coletadas, mais fidedigno será o resultado dos valores de referência dos animais saudáveis (LASSEN, 2006; 
GEFFRE et al., 2009; STOCKHAM ; SCOTT, 2011; FRIEDRICHS et al., 2012). Para uma precisão aceitável, determinou-se que 120 amostras devem ser analisadas para estabelecer um intervalo de referência. No entanto, na medicina veterinária esse número de 120 amostras frequentemente não é alcançado. Um número próximo de 60 indivíduos qualificados pode ser suficiente se uma distribuição gaussiana for obtida (STOCKHAM ; SCOTT, 2011). Por outro lado, segundo Lassen (2006) o número mínimo de amostras para estabelecer um intervalo de referência é de 40 animais, geralmente.

Existem vários métodos estatísticos para o estabelecimento do intervalo de referência. A escolha depende da distribuição dos valores obtidos a partir das amostras. Esses valores são traçados a partir de sua frequência de ocorrência, podendo formar uma distribuição normal, Gaussiana ou em formato de sino (Figura 1A). Com essa distribuição, testes paramétricos são apropriados para determinar o intervalo de referência. Em caso de distribuição não Gaussiana (Figura 1B) os testes paramétricos não são apropriados. Nesse caso, os dados são analisados por testes não paramétricos ou transformados para produzir uma distribuição normal, podendo, assim, ser analisados por testes paramétricos. Uma abordagem alternativa e prática é assumir que toda distribuição não é normal e aplicar métodos não paramétricos para determinação do intervalo de referência (LASSEN, 2006).

Convencionalmente, o intervalo de referência compreende 95\% dos valores de referência e são representados pelos valores menores e maiores dos limites de referência. $O$ método estatístico selecionado para determinação do intervalo de referência é baseado no número e distribuição dos valores de referência (Tabela 2) (FRIEDRICHS et al., 2012). 
Figura 1. Duas distribuições de valores. (A) Traçado com sua frequência de ocorrência, os valores formam uma distribuição simétrica, curva em formato de sino. Conhecido como distribuição Gaussiana. (B) Traçado com sua frequência de ocorrência, os valores formam uma distribuição assimétrica inclinada para os valores mais altos. Esta não é uma distribuição normal ou nãoGaussiana.

Fonte: STOCKAM ; SCOTT, 2011

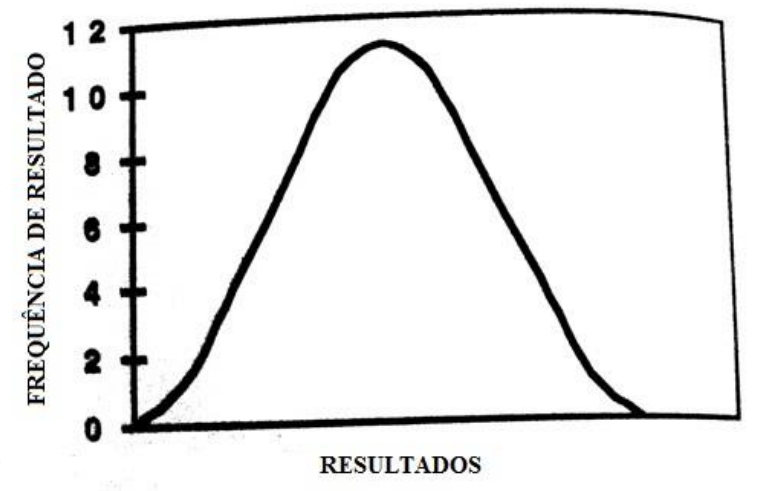

(A)

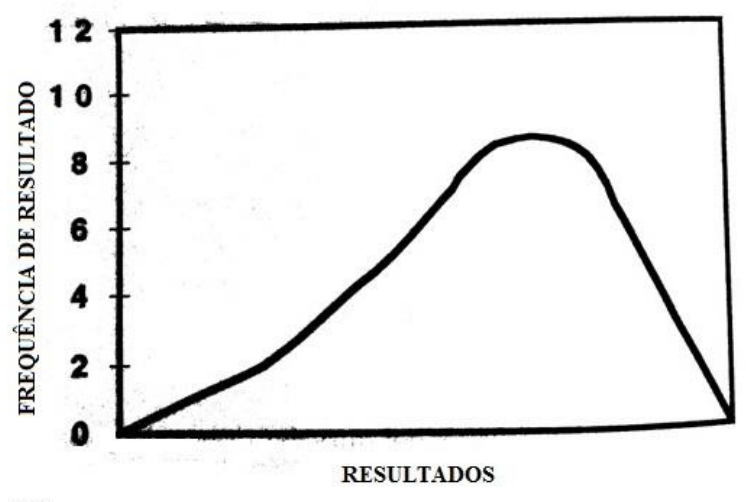

(B)

Tabela 2. Procedimentos recomendados para estabelecimento do intervalo de referência baseado no tamanho da amostra e distribuição.

\begin{tabular}{|c|c|c|}
\hline Tamanho da amostra & $\begin{array}{c}\text { Distribuição dos dados (Não } \\
\text { transformados ou } \\
\text { transformados) }\end{array}$ & Método estatístico \\
\hline$\geq 120$ & Não aplicável & $\begin{array}{l}\text { Não paramétrico com } 90 \% \text { de } \\
\text { intervalo de confiança dos } \\
\text { limites de referência }\end{array}$ \\
\hline \multirow[t]{2}{*}{$40 \leq X \leq 120$} & Gaussiana & $\begin{array}{l}\text { Robusta com } 90 \% \text { de intervalo } \\
\text { de confiança dos limites de } \\
\text { referência } \\
\text { Paramétrica com } 90 \% \text { de } \\
\text { intervalo de confiança dos } \\
\text { limites de referência }\end{array}$ \\
\hline & Não Gaussiana & $\begin{array}{l}\text { Robusta com } 90 \% \text { do intervalo } \\
\text { de confiança dos limites de } \\
\text { referência (Preferível) } \\
\text { Não paramétrica * }\end{array}$ \\
\hline \multirow[t]{2}{*}{$20 \leq x \leq 40$} & Gaussiana & $\begin{array}{l}\text { Paramétrica com } 90 \% \text { de } \\
\text { intervalo de confiança dos } \\
\text { limites de referência } \S\end{array}$ \\
\hline & Não Gaussiana & $\begin{array}{l}\text { Robusta com } 90 \% \text { de intervalo } \\
\text { de confiança dos limites de } \\
\text { referência }\end{array}$ \\
\hline $10 \leq x \leq 20$ & Não aplicável & $\begin{array}{l}\text { Não calcular intervalo de } \\
\text { referência }\end{array}$ \\
\hline$<10$ & Não aplicável & $\begin{array}{l}\text { Não calcular intervalo de } \\
\text { referência }\end{array}$ \\
\hline
\end{tabular}

Fonte: FRIEDRICHS et al.,2012 
* Não é possível determinar $90 \%$ de intervalo de confiança com método não-paramétrico com < 120 referência amostrais; métodos alternativos, por exemplo, bootstrap, exigido.

$\S$ Incluir o seguinte: histograma, média ou mediana, mínimo e máximo; alternativamente, demonstrar uma tabela com todos os valores de referência e histograma.

\subsubsection{Procedimentos pré-analíticos, analíticos e pós-analíticos do exame laboratorial}

A realização de um exame laboratorial passa por três fases: a fase préanalítica, analítica e pós-analítica. A fase pré-analítica consiste na atenção dada ao paciente e à coleta do material ou amostra, sendo esta, a principal fase para elaboração de intervalo de referência fidedigno. $\mathrm{Na}$ fase analítica, realiza-se a análise dos analitos em questão em determinados laboratórios. E, por fim, a fase pós-analítica compreende o laudo do exame e a tomada de decisão (LASSEN, 2006; STOCKHAM ; SCOTT, 2011; WALTON, 2012).

A fase pré-analítica tende a ser uma das mais importantes, pois é nesta fase que todo procedimento deve ser padronizado a fim de reduzir variações interindividuais e intra-individuais para análise de um intervalo de referência (FRIEDRICHS et al., 2012). A tabela 3 evidencia alguns dos fatores pré-analíticos importantes a serem padronizados. Um estudo realizado por Parker ; Blowey (1974) encontrou uma pequena, porém significante diferença estatística entre os níveis de hematócrito, hemoglobina, albumina, potássio e magnésio de sangue coletado da veia jugular de vacas. Contrariamente, estudo realizado, em 1994, comparando sangue coletado de veia cefálica e da veia jugular externa em cães, a maioria dos analitos não apresentou diferença, segundo o local de coleta, exceto dois deles, o potássio e a albumina, que mostraram níveis maiores quando coletados da veia jugular externa.

Sabe-se que a agregação celular tende a ser mais pronunciada quanto mais o sangue for resfriado e armazenado; consequentemente, quanto mais rápido o processamento das amostras menor será a formação de agregados leucocitários e/ou plaquetários (HARVEY, 2012). A refrigeração pode também resultar em aumento de atividade da enzima ALT (alanina aminotransferase), enquanto que a CK (creatinaquinase) deve ser analisada o quanto antes, devido à diminuição da 
atividade após 24 horas da coleta, independentemente das condições de armazenamento (WEISER, 2006).

Tabela 3. Fatores pré-analíticos para consideração e padronização com base no conhecimento prévio do analito e seus efeitos sobre a qualidade e os resultados das amostras

Fator pré-analítico

Preparação do paciente e manejo

Coleta da amostra

Manejo da amostra

Tempo de coleta

Estabilidade do analito
Exemplos

Com ou sem jejum

Método de captura ou contenção

Uso de sedação ou anestesia geral

Local (Jugular externa, cefálica, coccígea)

Preparo do local

Anticoagulante

Sistema de coleta (agulha, seringa, tubo)

Transporte

Temperatura

Centrifugação

Ritmos circadianos, flutuações sazonais, especialmente para hormônios

Condições de armazenamento

Fonte: FRIEDRICHS et al., 2012

No que se diz respeito à variação interracial, o cão é a espécie terrestre mais polimórfica do planeta. O Kennel Club do Reino Unido reconheceu cerca de 200 raças diferentes, cada uma com comportamento e características particulares que foram selecionadas artificialmente pelos humanos durante 500 anos. O resultado foi um alto grau de heterogeneidade interracial, mas perceptível homogeneidade intraracial (LINDBLAD-TOH et al., 2005). Mesmo quando se comenta sobre a homogeneidade intrarracial, há estudos que reforçam alguns elementos importantes a serem lembrados, principalmente, quando se trata de intervalo de referência. 
No grande estudo realizado por Lawrence et al. (2013), cerca de 6.046 exames hematológicos de cães de diferentes raças foram analisados, retrospectivamente, para avaliar suas divergências. Além de considerar as diferenças entre as raças, os autores ressaltaram diferenças, dentro de uma mesma raça, relacionadas à idade, ao sexo e ao estado reprodutivo (castrado ou não castrado). Todas as outras mensurações, exceto a concentração de hemoglobina corpuscular média ( $\mathrm{CHCM}$ ) variaram com a idade. Hemácias, hematócrito e hemoglobina apresentaram um padrão similar, os níveis foram aumentando até dois a quatro anos idade e diminuindo, posteriormente. Outro dado interessante foi que cães castrados apresentaram menores variações dos resultados citados.

Os parâmetros bioquímicos também já foram bastante estudados, principalmente para se reconhecer os efeitos da idade, sexo e estado reprodutivo do animal. O grupo de Chang et al. (2016) analisou 3045 amostras de parâmetros bioquímicos de cães, quais sejam proteína total, albumina, globulina, sódio, potássio, cloro, cálcio, fósforo, ureia, creatinina, colesterol, bilirrubina total, ALT, FA, creatina-quinase (CK), amilase, lipase e glicose, sendo que todos estes estavam dentro dos intervalos de referência, para avaliar as diferenças entre eles. Idade, sexo e estado reprodutivo impactaram em muitos dos analitos bioquímicos. Os níveis de cálcio, fósforo e fosfatase alcalina $(F A)$ foram maiores em cães mais jovens, enquanto que a creatinina demonstrou aumento e depois uma diminuição com a idade. Em relação à ureia, esta diminui seus níveis até seis a oito anos de idade e aumenta com mais de 10 anos. O potássio mostrou-se crescente com 0 passar dos anos. Houve diferenças entre machos e fêmeas, quando analisadas a proteína total, globulina e creatinina, e estas foram maiores em machos (CHANG et al.,2016).

A idade é fator pré-analítico importante a se determinar; estudos como os de Harper et al. (2003) e Rosset et al. (2012) demonstraram as variáveis que ocorrem durante o crescimento do animal e ambos estudos comprovaram a diferença de valores em animais mais jovens, portanto, um intervalo de referência deve ser atribuído a essa faixa etária.

$\mathrm{Na}$ fase analítica do exame laboratorial, a amostra deve ser analisada com métodos rigorosos e com procedimento de controle de qualidade apropriados. As condições de análise devem ser bem definidas, como por exemplo o lote de reagentes, bem como os técnicos envolvidos são algumas das variáveis a serem 
padronizadas com o intuito de reduzir as possíveis variações, que não estejam relacionadas às variações intrarracial ou interracial (FRIEDRICHS et al., 2012).

Concluindo, a fase pós-analítica compreende a confecção do laudo e tomada de decisão, que dependem diretamente das duas primeiras fases acima citadas, evidenciando, assim, a importância dos intervalos de referências em uma rotina diária e, consequentemente, sua tomada de decisão e estabelecimento de um diagnóstico (FRIEDRICHS et al, 2012).

\subsection{A COMPOSIÇÃO DO SANGUE}

O sangue é composto de células (eritrócitos, leucócitos e plaquetas), que circulam dentro de um fluido denominado plasma. Os eritrócitos ou células vermelhas são as mais numerosas e, dependendo da espécie, os eritrócitos tendem ser em torno de um quarto ou metade do volume total de sangue, que é mensurado pela determinação do hematócrito. As plaquetas ou trombócitos são as próximas células mais numerosas a compor o sangue e, por fim, os leucócitos são as células menos numerosas dentre elas (HARVEY, 2012). O esquema de composição sanguínea para o cão segue ilustrado na Figura 2.

O plasma é uma solução aquosa contendo componentes de pequeno e de elevado peso molecular, que correspondem a $10 \%$ do seu volume. As proteínas plasmáticas correspondem a $7 \%$ e os sais inorgânicos a $0,9 \%$, sendo o restante formado por compostos orgânicos diversos, entre eles: aminoácidos, vitaminas, hormônios e glicose. As principais proteínas do plasma são: albumina, alfa, beta e gamaglobulinas, lipoproteínas e as proteínas que participam da coagulação sanguínea, como protrombina e fibrinogênio (HARVEY, 2012). 
Figura 2. Composição sanguínea aproximada de um cão normal

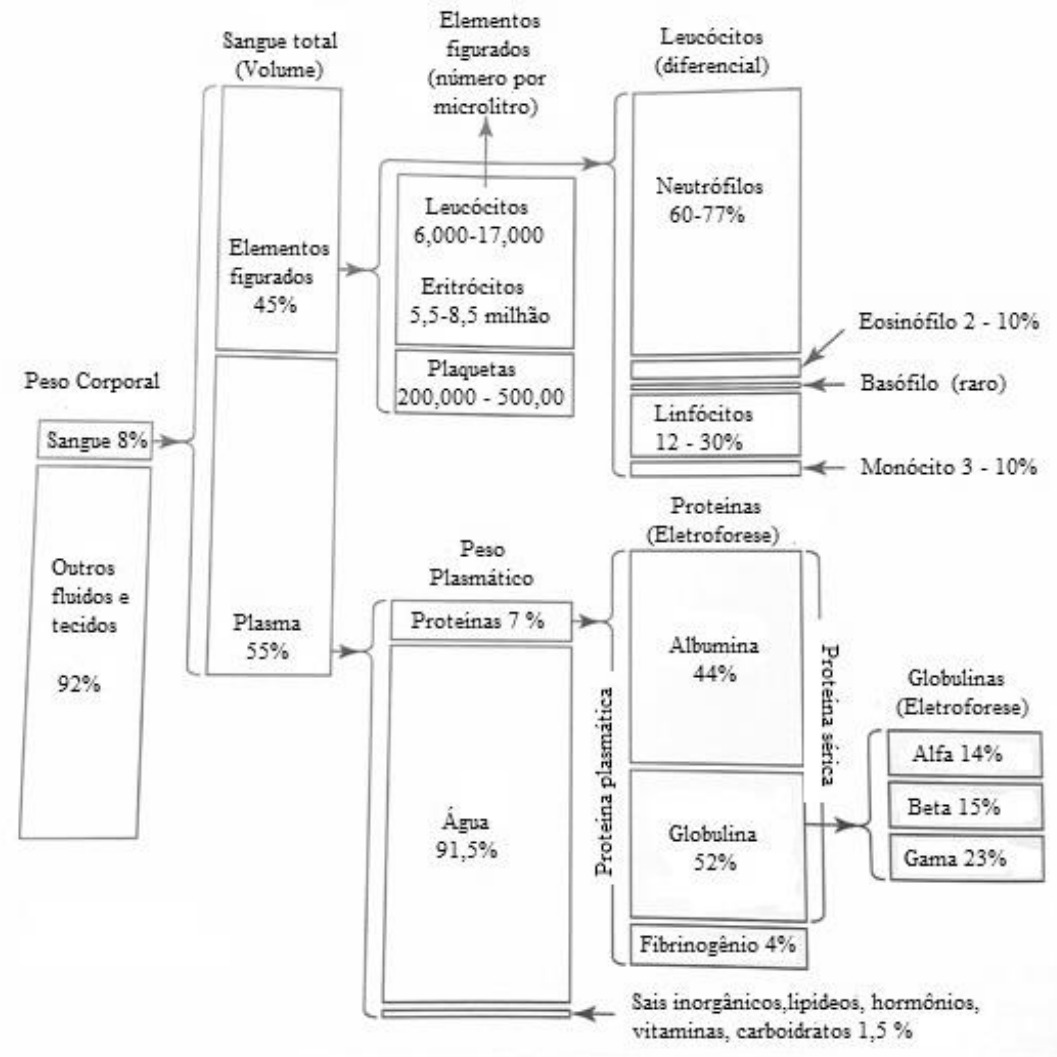

Fonte: HARVEY, 2012

\subsubsection{Hematopoiese}

Nos mamíferos, a hematopoiese primitiva inicia-se fora do corpo do embrião, no saco vitelínico e, posteriormente, na região aorta-gônada-mesonefro do embrião. Pequenos conglomerados de células-tronco já foram identificadas ligadas ao endotélio do saco vitelínico e na aorta dorsal (HARVEY, 2012). Posteriormente, o fígado e baço também funcionam como órgãos hematopoiéticos temporários, porém no segundo mês de vida intra-uterina, a clavícula já começa a ossificar e tem início a formação de medula óssea hematógena em seu interior. Conforme a ossificação do resto do esqueleto avança, a medula óssea torna-se, cada vez, mais importante como órgão hematopoiético (HARVEY, 2012).

$\mathrm{Na}$ vida pós-natal, eritrócitos, granulócitos, linfócitos, monócitos e plaquetas originam-se a partir de células-tronco da medula óssea vermelha (CAR, 2010). As células-tronco originam células filhas que seguem dois destinos: algumas 
permanecem como células-tronco, mantendo a população destas células e outras se diferenciam em outros tipos celulares com características específicas. Assim sendo, todas células sanguíneas derivam de um único tipo celular da medula óssea, por isso são denominadas células-tronco pluripotentes. Tais células proliferam e formam duas linhagens: a de células linfoides, que vão originar os linfócitos, e a das células mieloides, que originam os eritrócitos, granulócitos, monócitos e plaquetas (CAR, 2010; HARVEY, 2012).

A hematopoiese resulta na proliferação e diferenciação simultâneas de células-tronco que, conforme se diferenciam, reduzem sua potencialidade $e$ aumentam sua frequência de mitose. Tal processo depende de microambiente adequado e da presença de fatores de crescimento, também chamados de fatores estimuladores de colônia (CAR, 2010).

A medula óssea é encontrada no canal medular dos ossos longos e nas cavidades dos ossos esponjosos. Diferenciam-se em medula óssea vermelha, devido à presença de numerosos eritrócitos em diversos estágios de maturação, e em medula óssea amarela, rica em células adiposas e que não produz células sanguíneas (JUNQUEIRA; CARNEIRO, 2004; JAIN, 1993).

\subsubsection{Eritropoiese}

A função primária do eritrócito é o transporte de hemoglobina, que conduz oxigênio para os tecidos. A membrana permeável e deformável que envolve os componentes das células vermelhas é composta de lipídeos, proteínas e carboidratos. Os eritrócitos dos mamíferos são anucleados, arredondados e bicôncavos. Tal formato de disco bicôncavo é eficiente para troca de oxigênio e permite que a célula se deforme conforme se move pela vasculatura com um diâmetro menor (THRALL, 2006; OLVER, 2010).

O processo básico da maturação eritrocitária consiste na síntese de hemoglobina e na formação de um corpúsculo pequeno e bicôncavo que facilita a troca de oxigênio. A eritropoiese primitiva inicia-se e predomina no saco vitelínico, mas também ocorre, mais tardiamente, no fígado. Os eritrócitos primitivos são maiores, geralmente nucleados com uma relação núcleo:citoplasma maior. Assim, durante sua maturação, a célula diminuiu de volume, bem como o núcleo, até este 
apresentar-se picnótico e, finalmente, ser expulso da célula. De acordo com o grau de maturação, as células eritrocitárias são chamadas de: rubriblastos, prorubriblastos, rubrócito basofílico, rubrócito policromatofílico, metarubrócito, reticulócitos e hemácias (HARVEY, 2012).

O desenvolvimento de um reticulócito numa hemácia madura é um processo gradual que requer alguns dias dependendo da espécie envolvida. A sua maturação inicia-se na medula óssea e é completada no sangue periférico e baço, em cães, gatos e suínos (OLVER, 2010; STOCKHAM; SCOTT, 2011).

Aminoácidos, ácidos graxos, diversos minerais e vitaminas são essenciais para a eritropoiese. O ferro é necessário para a síntese de hemácias, assim como é essencial para a hemoglobina e algumas enzimas. O cobre é importante na liberação de ferro do tecido para o plasma para o desenvolvimento das células eritroides (HARVEY, 2012).

Diversas citocinas atuam sinergicamente com a eritropoietina para estimular a replicação e a diferenciação da unidade eritroide formadora de blastos em célulastronco comprometidas, que respondem à eritropoietina tanto por divisão quanto por diferenciação em rubriblastos. A eritropoietina é um hormônio produzido principalmente pelo fígado fetal e pelo rim adulto. As células intersticiais peritubulares renais produzem eritropoietina em resposta à hipóxia renal (OLVER, 2010; STOCKHAM; SCOTT, 2011).

\subsection{Eritrograma}

No eritrograma, a avaliação morfológica dos eritrócitos corados é uma parte importante do mesmo, principalmente, se a anemia estiver presente. Nessa avaliação, conhecer o significado das diferentes colorações, tamanhos, formas e inclusões anormais ou demais características levam o clínico a uma melhor interpretação do eritrograma (STOCKAM; SCOTT, 2011).

O hematócrito $(\mathrm{Ht})$ é a porcentagem de volume sanguíneo preenchido pelos eritrócitos e, portanto, uma medida da capacidade de transporte de oxigênio pelo sangue. A hemoglobina $(\mathrm{Hb})$ é a quantidade em gramas de $\mathrm{Hb}$ por $100 \mathrm{~mL}$ de sangue. Essencialmente, toda $\mathrm{Hb}$ no sangue encontra-se nos eritrócitos, exceto em alguns poucos estados patológicos. Os eritrócitos ou hemácias representam o número de eritrócitos por unidade de volume de sangue. Os índices hematimétricos 
são em número de três: volume corpuscular médio (VCM), que é o volume médio de eritrócito; concentração de hemoglobina corpuscular média ( $\mathrm{CHCM})$, que é a concentração de hemoglobina celular média por eritrócito; e hemoglobina corpuscular média (HCM), que é a quantidade de hemoglobina média por eritrócito. A CHCM e o VCM são utilizados para classificar as anemias (STOCKHAM; SCOTT, 2011; HARVEY, 2012).

\subsubsection{Granulopoiese}

O mieloblasto é a célula mais imatura, determinada para formar exclusivamente os três tipos de granulócitos, quais sejam: neutrófilos, basófilos e eosinófilos. Quando surgem granulações citoplasmáticas específicas, o mieloblasto transforma-se em promielócito. Os estágios seguintes de maturação são: mielócito, metamielócito, granulócito com núcleo em bastão e granulócito maduro (neutrófilos, eosinófilos e basófilos) (JUNQUEIRA; CARNEIRO, 2004; STOCKHAM; SCOTT, 2011).

Os neutrófilos são as células em maior quantidade no sangue e passam por diversos compartimentos anatômicos e funcionais, que podem ser categorizados da seguinte maneira: 1. compartimento medular de formação, onde são produzidos e amadurecidos; 2. compartimento medular de reserva, onde ficam os neutrófilos maduros que são mantidos por um período variável, antes de serem lançados para a circulação periférica; 3. compartimento circulante, constituído por neutrófilos suspensos no plasma e circulando nos vasos sanguíneos; e 4. compartimento de marginação, apesar de estarem nos vasos sanguíneos, não circulam nos mesmos (JUNQUEIRA; CARNEIRO, 2004; OLVER,2010; HARVEY, 2012).

\subsubsection{Maturação de linfócitos e monócitos}

Tais células não apresentam grânulos específicos e nem núcleos lobulados, características que facilitam a distinção entre os diversos estágios dos granulócitos. Os precursores dos linfócitos são identificados, principalmente, por tamanho, estrutura da cromatina e presença de nucléolos visíveis nos esfregaços sanguíneos. Os linfócitos circulantes no sangue e na linfa originam-se do timo e dos órgãos 
linfoides periféricos, como baço, linfonodos e tonsilas, a partir de células trazidas da medula óssea pelo sangue. A célula mais jovem da linhagem é o linfoblasto, que forma o pró-linfócito, formando enfim os linfócitos maduros (JUNQUEIRA; CARNEIRO, 2004; STOCKHAM; SCOTT, 2011).

Os monócitos são células intermediárias que formam os macrófagos nos tecidos. A célula mais jovem da linhagem é o pró-monócito, encontrado na medula óssea. O pró-monócito divide-se duas vezes, transformando-se em monócitos que migram para o sangue, onde permanecem por algumas horas. Após esse período, destinam-se para 0 tecido conjuntivo, diferenciando-se em macrófagos (JUNQUEIRA; CARNEIRO, 2004; STOCKHAM; SCOTT, 2011).

\subsubsection{Trombopoiese}

As plaquetas, também denominadas trombócitos, originam-se na medula óssea vermelha pela fragmentação de pedaços do citoplasma dos megacariócitos e estes, por sua vez, formam-se pela diferenciação dos megacarioblastos (JUNQUEIRA; CARNEIRO, 2004).

A produção de plaquetas é influenciada principalmente pelo grau de estimulação de citocinas e pelo número de células responsivas. A vida média das plaquetas é de 5 a 10 dias em indivíduos sadios, na maioria das espécies animais. A mobilização e o armazenamento das plaquetas ocorrem principalmente no baço (STOCKHAM; SCOTT, 2011).

\subsubsection{Avaliação da função renal}

Existem dois tipos de definições bastante utilizadas quando o assunto é disfunção renal, entre elas: azotemia, que é o aumento de compostos nitrogenados não proteicos no sangue que são detectados pelo aumento de ureia e creatinina no sangue; e, uremia, que se refere às manifestações clínicas que refletem a disfunção renal (como êmese, diarreia, coma, convulsões, odor amoniacal da respiração entre outras (STOCKHAM; SCOTT, 2011).

A mensuração da ureia pode ser realizada no soro, no plasma ou no sangue total. É composta por um átomo de carbono, um de oxigênio, dois de nitrogênio e 
quatro de hidrogênio. A ureia representa o índice sanguíneo da filtração glomerular. De forma simplória, uma grande parte da ureia produzida pelo corpo é excretada na urina pela filtração glomerular. Portanto, a redução da taxa de filtração glomerular resultará em aumento na concentração de ureia. No entanto, a formação de ureia é afetada pela produção de ureia pelo fígado e pelas taxas de excreção de ureia por vias renais e extrarrenais. Assim, o aumento de ingestão de proteínas na dieta irá fornecer mais aminoácidos, que serão absorvidos pelo trato gastrintestinal após a digestão das proteínas. Este excesso de aminoácidos sofrerá desaminação oxidativa e contribuirá para o aumento hepático de produção de ureia (FETTMAN; REBAR, 2006).

A creatinina é formada pela condensação espontânea e desidratação da creatina muscular numa estrutura anelar. A quantidade diária de creatinina produzida é relativamente constante e não é afetada por fatores extrarrenais como a ureia. Assim que a creatinina é formada, esta é removida do corpo, quase que inteiramente, pela excreção renal por meio da filtração glomerular. Fatores como citocinas, que aumentam o catabolismo muscular em casos de sepse ou caquexia, podem aumentar a liberação de creatina e, assim, aumentar a quantidade de creatinina produzida (FETTMAN; REBAR, 2006).

\subsubsection{Avaliação da função hepática}

O fígado possui muitas funções fisiológicas envolvendo síntese, excreção e armazenamento. No tocante à síntese, os hepatócitos sintetizam a maioria das proteínas plasmáticas, incluindo a albumina e a maioria das globulinas. Os hepatócitos também removem a maior parte da glicose dietética do sangue portal e armazenam glicose, sob a forma de glicogênio, para necessidades emergenciais, glicose esta que, a partir da gliconeogênese hepática, serve de fonte de energia para os animais em jejum, além de produzir ácidos graxos, triglicerídeos e colesterol. Ainda, como função hepática, os hepatócitos modificam ou degradam compostos endógenos e exógenos. Finalmente, os hepatócitos modificam compostos em formas hidrossolúveis para excreção pelos sistemas biliar, urinário ou intestinal (LASSEN, 2006; STOCKHAM; SCOTT, 2011).

Injúria aos hepatócitos é detectada por meio da mensuração de enzimas que extravasam dos mesmos; dentre essas enzimas, a alanina aminotransferase (ALT) 
acha-se livre no citoplasma e pode, também, estar presente em casos de dano muscular, não sendo totalmente específica do fígado. Assim, o aumento de ALT em cães e gatos, usualmente, é sugestivo de dano do hepatócito, mas injúria em células musculares também deve ser investigada. Já a enzima aspartato aminotransferase (AST) está presente em altas concentrações nos hepatócitos e células musculares, tanto esqueléticas quanto cardíacas, de todas as espécies. A AST também não é uma enzima específica do fígado e está livre no citoplasma e nas membranas da mitocôndria e, devido sua localização, tende a ser menos específica ao dano hepático do que a ALT. Outra enzima avaliada no perfil hepático é a fosfatase alcalina (FA), sintetizada pelo fígado, osteoblastos, epitélio intestinal, epitélio renal e placenta. Nos demais órgãos, a meia vida dessa enzima é relativamente baixa, portanto, seus níveis aumentados podem resultar em aumento da atividade osteoblástica, colestase, indução por certos fármacos e doenças crônicas. Finalmente, a avaliação laboratorial do fígado inclui as bilirrubinas. A bilirrubina é produzida constantemente a partir da degradação da fração heme, proveniente de eritrócitos senescentes, e de proteínas contendo heme. No estado de higidez, são rapidamente removidas do plasma pelo fígado ou pelos rins, portanto, o estado de hiperbilirrubinemia pode estar presente em doenças do parênquima hepático, como nas colestases hepáticas (LASSEN, 2006).

\subsection{O DACHSHUND}

Cães da raça Dachshund apresentam acondropasia/hipocondroplasia considerada uma condição fisiológica. $\mathrm{Na}$ medicina humana, a acondroplasia/hipocondroplasia afeta o osso endocondral induzindo o indivíduo a apresentar nanismo desproporcional, microcefalia, hipoplasia facial e alterações em coluna vertebral (GOUGH; THOMAS, 2010). Na idade média, os Dachshunds descenderam de cães da raça Braco, com o intuito de realizar caça subterrânea e, dessa forma, evoluíram para padrão racial de patas curtas versáteis para caça. Apresentam corpo longo com membros curtos, arqueados e musculosos (Enciclopédia do Cão, 2001), esterno largo e proeminente com a caixa torácica oval e ampla, com coração e pulmões bem desenvolvidos (Confederação Brasileira De Cinofilia, 2015 - http://www.cbkc.com.br/padroes/pdf/grupo4/dachshund.pdf; consulta em 10 de Maio de 2016). 
No ano de 2015, a raça Dachshund foi comparada com cães sem definição racial no que tange aos parâmetros hematológicos, concluindo-se que cães dessa raça apresentam valores maiores de hematócrito, eritrócitos e hemoglobina (TORRES et al., 2015). Neste estudo foram comparados 61 Dachshunds com 60 animais sem definição racial, constatando-se que os valores de hematócrito, eritrócitos e hemoglobina foram maiores nos primeiros. A possível justificativa seria uma contração esplênica em momentos de estresse, na qual haveria diminuição da oxigenação dos tecidos e, até mesmo, uma secreção inapropriada de eritropoietina (JAIN, 1993). Mas o trabalho relatado por Torres et al. (2015) refutou tal explicação, uma vez que os animais foram analisados em circunstâncias parecidas e apresentavam-se sadios e, principalmente, os autores atentaram-se ao estado de hidratação dos animais. O mesmo grupo conjecturou que pela raça ser condrodistrófica e ter sido geneticamente selecionada para caça subterrânea, o que pode ter ocorrido, é uma adaptação desses animais em ambientes com baixas tensões de oxigênio ao longo do tempo, assim como a adaptação para corrida dos cães da raça Greyhound.

\subsubsection{A variabilidade racial e os exames laboratoriais}

Diversos estudos de padronização de valores hematológicos já foram realizados e observaram-se particularidades raciais em condições fisiológicas. Campora et al. (2011) observaram altos valores referentes ao eritrograma (contagem global de hemácias, hemoglobina e hematócrito) e baixos valores relacionados à contagem global de leucócitos e plaquetas em cães da raça Greyhound, da mesma forma que o observado por Sullivan et al. (1994) e Shiel et al. (2007).

Nielsen et al. (2010) realizaram estudo com cães adultos e sadios da raça Bernese Mountain, comparando os valores hematológicos e bioquímicos com valores de referências já pré-estabelecidos para a espécie, concluindo que sete analitos hematológicos e bioquímicos, entre eles eosinófilos, concentração de hemoglobina corpuscular média, fosfatase alcalina, gama-glutamiltransferase, bilirrubina total, amilase e colesterol apresentaram diferença significativa, evidenciando a importância da variação racial e a relevância clínica no momento da interpretação laboratorial no auxílio do diagnóstico. 
Cães da raça Cavalier King Charles Spaniel foram estudados por apresentarem macrotrombocitopenia e descobriu-se que tal alteração representa uma herança autossômica recessiva, assintomática, sem evidências de anormalidades hemorrágicas, com resposta de agregação plaquetária normal e sem correlação com qualquer alteração clínica (PEDERSEN et al., 2002).

$\mathrm{Em}$ contrapartida, quando quatro raças (Malamute do Alaska, Husky Siberiano, Golden Retriever e Setter Inglês) foram comparadas em relação à bioquímica sérica, constatou-se diferença estatística entre elas; entretanto, a diferença observada foi pequena e sem relevância clínica (SHARKEY et al., 2009). 


\section{MATERIAL E MÉTODOS}

\subsection{COMISSÃO DE ÉTICA NO USO DE ANIMAIS}

Somente os tutores cientes e de acordo com a publicação dos dados dos animais foram incluídos; ademais, este projeto foi submetido à apreciação da Comissão de Bioética da FMVZ-USP ( $N^{\circ}$ CEUA 2658161015). O presente trabalho utilizou-se do termo de consentimento livre e esclarecido de projeto realizado concomitantemente.

\subsection{LOCAL DE REALIZAÇÃO}

O presente trabalho foi realizado nos Serviços de Laboratório Clínico e de Cardiologia do Departamento de Clínica Médica (VCM)/Hospital Veterinário da Faculdade de Medicina Veterinária e Zootecnia (FMVZ) da Universidade de São Paulo (USP).

\subsection{OS ANIMAIS}

Sessenta e nove cães adultos (acima de 15 meses) e clinicamente sadios da raça Dachshund foram atendidos no HOVET-USP, e encaminhados ao Serviço de Cardiologia para avaliação clínica e determinação da salubridade dos mesmos por meio de anamnese, exames físico, hematológicos e bioquímicos, ecocardiográfico e eletrocardiográfico, além da avaliação da pressão arterial sistêmica (PAS) pelo método Doppler. Os animais foram encaminhados, também, ao Serviço de Diagnóstico por Imagem do Departamento de Cirurgia/HOVET - FMVZ/USP para a realização das radiografias torácicas e ultrassonografia abdominal.

Os critérios de inclusão foram estabelecidos da seguinte maneira: dos animais considerados sadios, num projeto realizado concomitantemente a este, e atendidos nos diferentes serviços do HOVET - FMVZ - USP e outros provenientes de canis da raça Dachshund, cujos tutores/criadores aceitassem participar da pesquisa, coletou-se sangue para a realização deste projeto. Por outro lado, foram excluídos deste projeto animais com qualquer cardiopatia, nefropatia, hepatopatia, 
endocrinopatia e neoplasia. Na ilustração a seguir, o fluxograma dos animais do projeto (Gráfico 1).

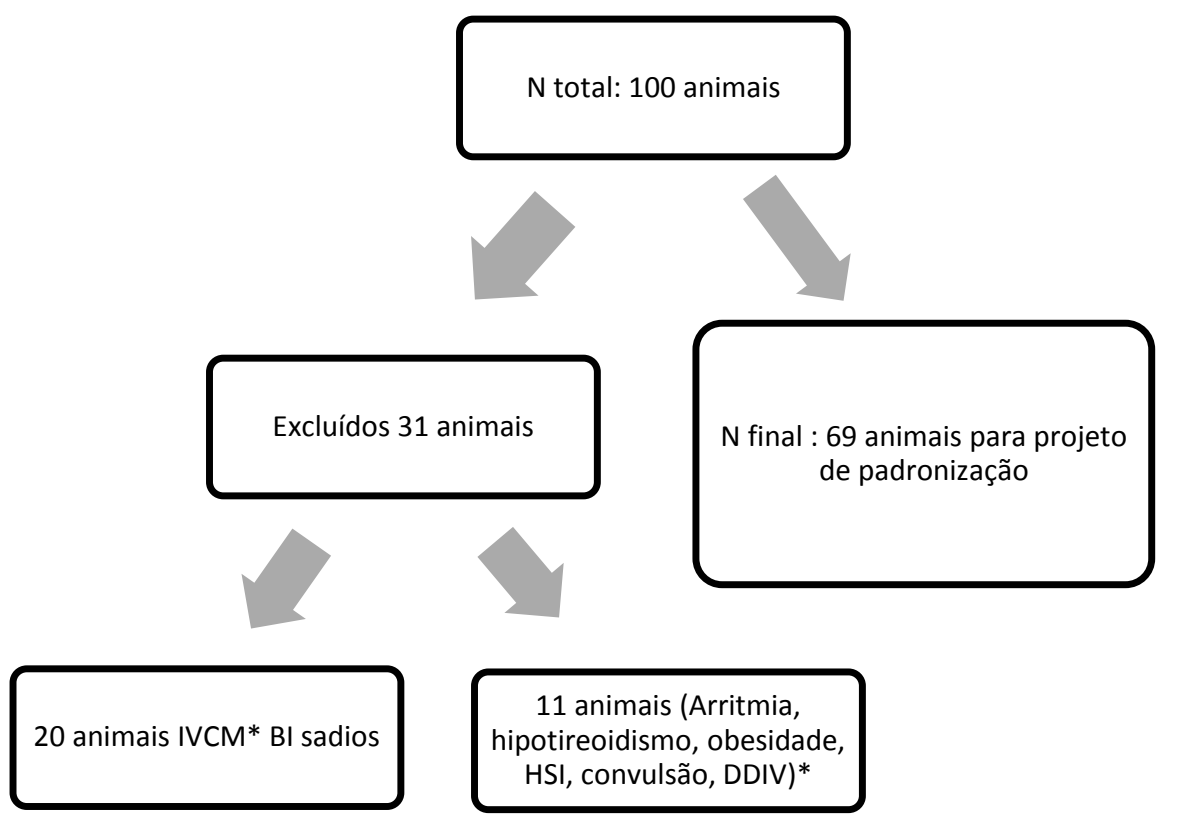

Gráfico 1. Fluxograma dos animais atendidos no Serviço de Cardiologia do HOVET-USP

* DDIV: doença do disco intervertebral; HSI: hipertrofia septo interventricular; IVCM: insuficiência valvar crônica de mitral.

\subsection{EXAMES LABORATORIAIS}

As amostras de sangue (aproximadamente $5 \mathrm{~mL}$ ) foram obtidas por meio de punção da veia jugular, com o animal previamente em jejum alimentar de 10 horas e, imediatamente, acondicionadas em tubos da marca $\mathrm{BD} \circledast$ contendo anticoagulante EDTA - ácido etilenodiamino tetracético (para a realização do hemograma completo) e contendo gel coagulante (para realização do perfil bioquímico). Os tubos contendo gel foram centrifugados a 5000 rpm (rotações por minutos), por cinco minutos, para 
a obtenção do soro e realização de exames bioquímicos (perfil hepático e perfil renal).

O hemograma foi realizado em contador hematológico automático, para uso veterinário, da marca Advia ${ }^{\circledR}$, modelo 2120i, determinando-se as contagens totais de hemácias, leucócitos, hemoglobina, volume globular e plaquetas. A contagem diferencial de leucócitos foi realizada por microscopia óptica do esfregaço sanguíneo com sangue in natura, confeccionado no momento da coleta das amostras, e corados pela técnica de Rosenfeld.

Para a realização do perfil bioquímico completo, utilizou-se analisador bioquímico automático da marca LABTEST, modelo LABMAX 240. O perfil hepático incluiu dosagens séricas de fosfatase alcalina (FA), alanino aminotransferase (ALT), proteína total e albumina. O perfil renal foi determinado pela realização de dosagens séricas de ureia e creatinina.

Para a determinação das proteínas totais foi aplicado o método colorimétrico de biureto, segundo Gornall et al. (1949) (GORNALL; BARDAWILL; DAVID, 1949) e, para a dosagem de albumina, o método colorimétrico de verde de bromocresol (CORCORAN; DURHAM, 1977). A atividade enzimática da alanina aminotransferase $(A L T)$, da fosfatase alcalina (FA) e bem como as dosagens das bilirrubinas total, direta e indireta foram determinadas segundo protocolo do "kit" do fabricante Biosystems AS (Barcelona, Spain).

Em relação à avaliação do perfil renal, ureia e creatinina, estas foram mensuradas de acordo com as recomendações dos fabricantes Diasys (Holzheim, Germany) e Labtest (Lagoa Santa, Minas Gerais), respectivamente.

Esses exames foram realizados no Laboratório Clínico do VCM/ HOVET/FMVZ-USP.

\subsection{ANÁLISE ESTATÍSTICA}

Para a análise dos dados obtidos, realizou-se a avaliação dos histogramas e teste de normalidade de Shapiro-Wilk para determinação da distribuição dos parâmetros analisados, se paramétrica ou gaussiana e não-paramétrica ou nãogaussiana. Para determinação de tendência central e dispersão, para aquela classificada como gaussiana, utilizou-se de média e desvio padrão, e para as nãogaussianas, utilizou de mediana e percentis $25\left(\mathrm{P}_{25 \%}\right)$ e $75\left(\mathrm{P}_{75 \%}\right)$. Para comparação 
de dois grupos de parâmetros com distribuição gaussiana não pareados utilizou-se do teste $t$, enquanto que para aqueles com distribuição não-gaussiana utilizou-se do teste de Mann-Whitney. 


\section{RESULTADOS}

Dos 69 animais incluídos no projeto, 28 eram machos e 41 fêmeas. Em relação à idade, os animais foram divididos em dois subgrupos: abaixo de seis anos, 43 animais, e acima de seis anos, com 26 animais, para a análise comparativa adiante. Foram avaliados 23 parâmetros, sendo eles: contagem total de hemácias $(\mathrm{He})$, hemoglobina $(\mathrm{Hb})$, hematócrito $(\mathrm{Ht})$, volume corpuscular médio (VCM), concentração de hemoglobina corpuscular média ( $\mathrm{CHCM})$, hemoglobina corpuscular média (HCM), contagem total de leucócitos, neutrófilos totais, metamielócitos, bastonetes, segmentados, linfócitos típicos, linfócitos atípicos, monócitos, eosinófilos, basófilos, plaquetas, proteína total, albumina, ALT, FA, ureia e cretinina. Para todos esses parâmetros foram realizados histogramas para avaliação da distribuição dos dados, como segue ilustrado na figura 3, realizando, também, teste de normalidade Shapiro-Wilk.

Para avaliação de tendência central e dispersão do eritrograma, encontraram-se valores médios de hemácias $\left(8,2 \times 10^{6} / \mu \mathrm{L} \pm 0,74\right)$, hemoglobina $(18,98 \mathrm{~g} / \mathrm{dL} \pm 1,60)$, hematócrito $(55 \% \pm 5,0)$ e VCM $(66,2 \mathrm{fL} \pm 2,71)$; e as medianas de HCM (23 pg, $\mathrm{P}_{25}$ $75,22-24)$ e $\mathrm{CHCM}\left(35 \%, \mathrm{P}_{25-75}, 34-35,05\right)$ (tabela 4). No referente ao leucograma, foram obtidos valor médio de leucócitos $(9.119 \mu / L \pm 2402)$ e valores de medianas de neutrófilos totais $\left(6080 \mu / L, P_{25-75}, 4942-7657\right)$, neutrófilos segmentados $(6080 \mu / L$, $\left.\mathrm{P}_{25-75}, 4942-7657\right)$, linfócitos típicos (1730 $\left.\mu / L, P_{25-75}, 1371-2275\right)$, monócitos (430 $\left.\mu / L, P_{25-75}, 303-595\right)$, eosinófilos (230 $\left.\mu / L, P_{25-75}, 171-430\right)$ e basófilos $\left(0 \mu / L, P_{25-75}\right.$, 0-60). Não foram encontrados valores para avaliação dos parâmetros de metamielócitos, bastonetes, linfócitos atípicos (Tabela 5) e o valor médio de plaquetas foi 307,3 $\times 10^{3} / \mu \mathrm{L}, \pm 76,81$ (Tabela 4). Na avaliação bioquímica do perfil renal, foram obtidos valores médios de ureia $(34,59 \mathrm{mg} / \mathrm{dL} \pm 10,36)$ e creatinina $(0,82 \mathrm{mg} / \mathrm{dL} \pm 0,12)$ e para o perfil hepático, valores médios de proteína total $(\mathrm{Pt})$ $(6,86 \mathrm{~g} / \mathrm{dL} \pm 0,50)$ e albumina $(4,19 \mathrm{~g} / \mathrm{dL} \pm 0,26)$, e valores de mediana para ALT $\left(26,9 \mathrm{U} / \mathrm{L}, \mathrm{P}_{25-75,} 21,5-34,4\right)$ e FA $\left(20,5 \mathrm{U} / \mathrm{L}, \mathrm{P}_{25-75}, 14-28,1\right)$. (Tabela 6$)$. 

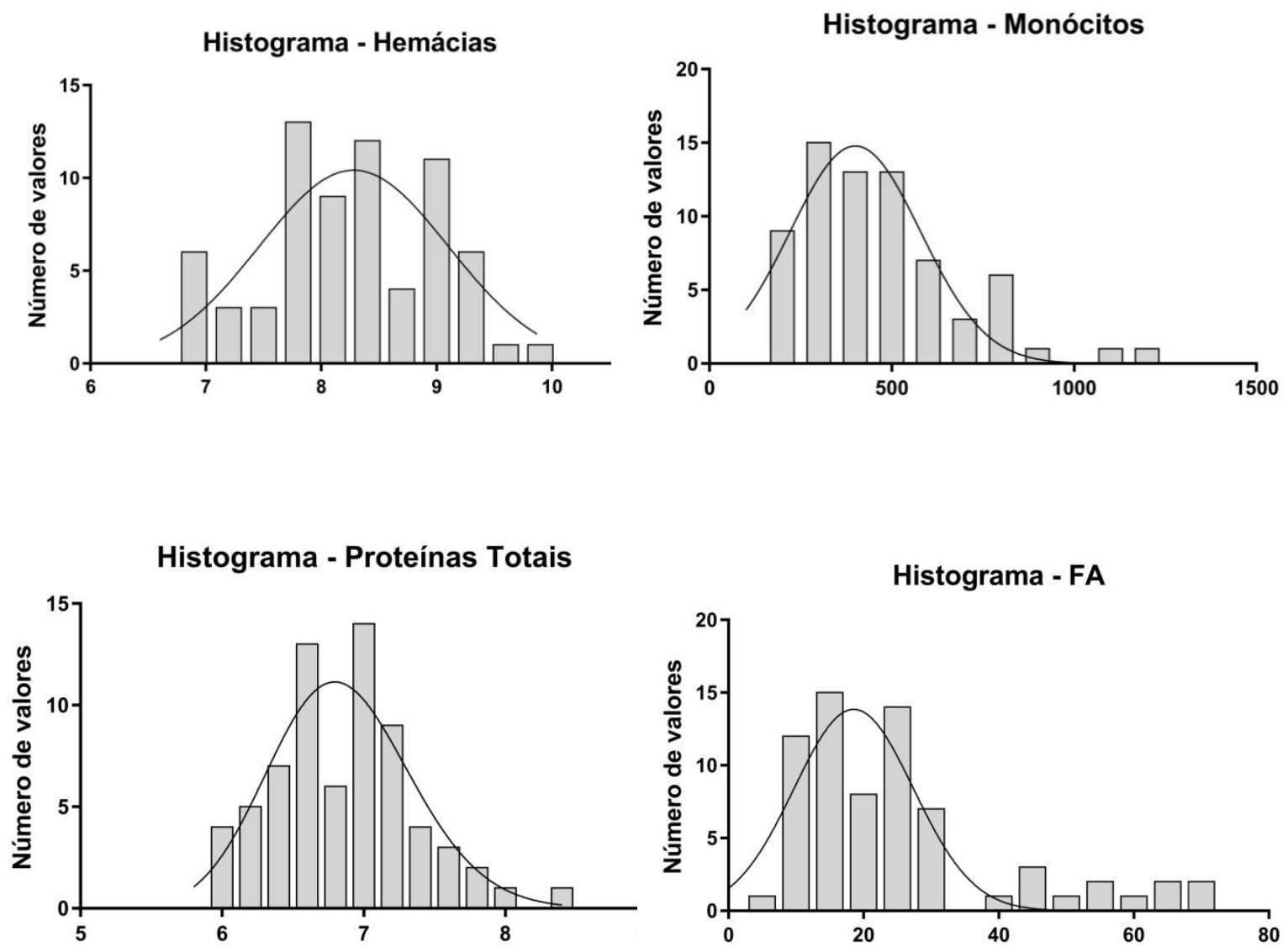

Histograma - Hematócrito
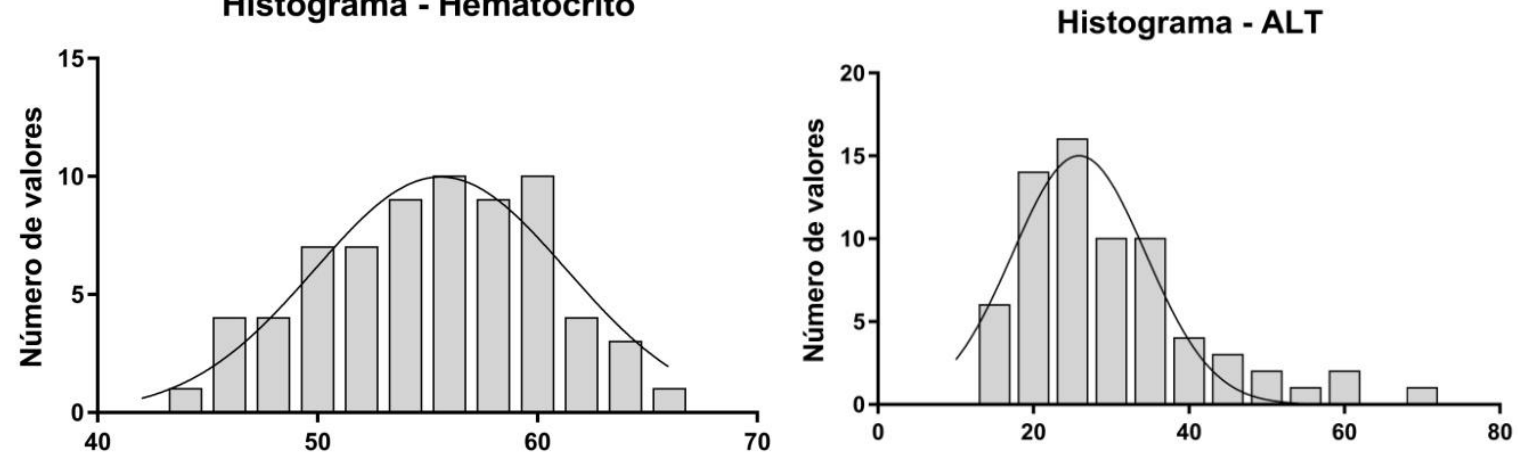

Gráfico 2. Histogramas das distribuições de valores obtidos das análises hematológicas e bioquímicas de cães adultos da raça Dachshund.

Legenda: Histogramas da esquerda com representação de distribuição gaussiana e, da direita, com distribuição não-gaussiana. 
Tabela 4. Valores dos parâmetros do eritrograma de cães adultos da raça Dachshund.

\begin{tabular}{|c|c|c|c|c|c|c|c|}
\hline PARÂMETROS & $\begin{array}{c}\text { Hemácias } x \\
10^{6} / \mu \mathrm{L}\end{array}$ & $\begin{array}{l}\text { Hemoglobina } \\
(\mathrm{g} / \mathrm{dL})\end{array}$ & $\begin{array}{c}\text { Hematócrito } \\
\text { (\%) }\end{array}$ & $\begin{array}{l}\text { VCM } \\
\text { (fL) }\end{array}$ & $\begin{array}{l}\text { HCM } \\
(p g)\end{array}$ & $\begin{array}{c}\mathrm{CHCM} \\
(\%)\end{array}$ & $\begin{array}{c}\text { Plaquetas } \\
\qquad\left(\mathrm{mm}^{3}\right)\end{array}$ \\
\hline $\begin{array}{l}\text { Número } \\
\text { amostral }\end{array}$ & 69 & 69 & 69 & 69 & 69 & 69 & 69 \\
\hline Mínimo & 6,77 & 15,3 & 43 & 60 & 21 & 25,7 & 128 \\
\hline Percentil 25\% & 7,7 & 18,1 & 51,05 & 64,85 & 24 & 34 & 253 \\
\hline Mediana & 8,3 & 19 & 55 & 66 & 23 & 35 & 302 \\
\hline Percentil 75\% & 8,9 & 20,1 & 59 & 68 & 24 & 35,05 & 359,5 \\
\hline Máximo & 9,9 & 22,4 & 65 & 73 & 26 & 40 & 500 \\
\hline Média & 8,26 & 18,98 & 54,78 & 66,28 & 22,94 & 34,61 & 307,3 \\
\hline Desvio padrão & 0,7458 & 1,605 & 5,002 & 2,713 & 1,036 & 1,535 & 76,81 \\
\hline $\begin{array}{c}\text { Nível de } \\
\text { confiança real }\end{array}$ & $97,05 \%$ & $97,05 \%$ & $97,05 \%$ & $97,05 \%$ & $97,05 \%$ & $97,05 \%$ & $97,05 \%$ \\
\hline $\begin{array}{c}\text { Menor limite de } \\
\text { confiança }\end{array}$ & 8 & 18,6 & 53,4 & 65,1 & 22,5 & 34 & 276 \\
\hline $\begin{array}{c}\text { Menor limite de } \\
\text { confiança }\end{array}$ & 8,5 & 19,5 & 57 & 67 & 23,1 & 35 & 324 \\
\hline \multicolumn{8}{|l|}{$\begin{array}{c}\text { Teste de } \\
\text { Shapiro Wilk }\end{array}$} \\
\hline Valor de $p$ & 0,3471 & 0,3213 & 0,5753 & 0,7633 & 0,0003 & $<0,0001$ & 0,7179 \\
\hline
\end{tabular}


Tabela 5. Valores dos parâmetros do leucograma de cães adultos da raça Dachshund.

\begin{tabular}{|c|c|c|c|c|c|c|c|c|}
\hline PARÂMETROS & Leucócitos $/ \mathrm{mm}^{3}$ & Neutrófilos & Segmentados & $\begin{array}{l}\text { Linfócitos } \\
\text { Típicos }\end{array}$ & Monócitos & Eosinófilos & Basófilos & $\begin{array}{l}\text { Metemielócitos, } \\
\text { Bastonetes } \\
\text { Linfócitos } \\
\text { atípicos }\end{array}$ \\
\hline $\begin{array}{l}\text { Número } \\
\text { amostral }\end{array}$ & 69 & 69 & 69 & 69 & 69 & 69 & 69 & 69 \\
\hline Mínimo & 4300 & 2814 & 2814 & 867 & 178 & 30 & 0 & 0 \\
\hline Percentil 25\% & 7700 & 4942 & 4952 & 1371 & 303 & 171 & 0 & 0 \\
\hline Mediana & 8800 & 6080 & 6080 & 1730 & 430 & 280 & 0 & 0 \\
\hline Percentil 75\% & 10395 & 7657 & 7657 & 2275 & 595 & 430 & 60 & 0 \\
\hline Máximo & 15450 & 12350 & 12350 & 3270 & 1180 & 4218 & 160 & 0 \\
\hline Média & 9119 & 6449 & 6449 & 1844 & 466,9 & 414,5 & 32,16 & 0 \\
\hline Desvio padrão & 2402 & 2145 & 2145 & 594,2 & 210,6 & 586,3 & 41,12 & 0 \\
\hline $\begin{array}{c}\text { Nível de } \\
\text { confiança real }\end{array}$ & $97,05 \%$ & $97,05 \%$ & $97,05 \%$ & $97,05 \%$ & $97,05 \%$ & $97,05 \%$ & $97,05 \%$ & $97,05 \%$ \\
\hline $\begin{array}{c}\text { Menor limite de } \\
\text { confiança }\end{array}$ & 8360 & 5456 & 5456 & 1575 & 350 & 250 & 0 & 0 \\
\hline $\begin{array}{l}\text { Maior limite de } \\
\text { confiança }\end{array}$ & 9630 & 6867 & 6867 & 1970 & 500 & 340 & 40 & 0 \\
\hline $\begin{array}{c}\text { Teste de } \\
\text { Shapiro Wilk }\end{array}$ & & & & & & & & \\
\hline Valor de $p$ & 0,1031 & 0,013 & 0,013 & 0,0443 & 0,0005 & $<0,0001$ & $<0,0001$ & - \\
\hline
\end{tabular}


Tabela 6. Valores dos parâmetros de função hepática e renal de cães adultos da raça Dachshund.

\begin{tabular}{|c|c|c|c|c|c|c|}
\hline PARÂMETROS & $\begin{array}{l}\text { Proteínas totais } \\
(\mathrm{g} / \mathrm{dL})\end{array}$ & $\begin{array}{c}\text { Albumina } \\
\text { (g/dL) }\end{array}$ & $\begin{array}{l}\text { ALT } \\
(\mathrm{U} / \mathrm{L})\end{array}$ & $\begin{array}{c}\text { FA } \\
(U / L)\end{array}$ & $\begin{array}{c}\text { Uréia } \\
\text { (mg/dL) }\end{array}$ & $\begin{array}{c}\text { Creatinina } \\
\text { (mg/dL) }\end{array}$ \\
\hline Número amostral & 69 & 69 & 69 & 69 & 69 & 69 \\
\hline Mínimo & 5,94 & 3,69 & 13,7 & 4,1 & 10,3 & 0,59 \\
\hline Percentil 25\% & 6,515 & 3,965 & 21,5 & 14 & 29 & 0,73 \\
\hline Mediana & 6,89 & 4,22 & 26,9 & 20,5 & 33,7 & 0,81 \\
\hline Percentil $75 \%$ & 7,14 & 4,39 & 34,8 & 28,1 & 39,6 & 0,905 \\
\hline Máximo & 8,3 & 4,86 & 68,4 & 71,6 & 71,4 & 1,18 \\
\hline Média & 6,862 & 4,199 & 29,78 & 25,27 & 34,59 & 0,8259 \\
\hline Desvio padrão & 0,5001 & 0,2677 & 11,67 & 15,84 & 10,36 & 0,1212 \\
\hline $\begin{array}{c}\text { Nível de confiança } \\
\text { real }\end{array}$ & $97,05 \%$ & $97,05 \%$ & $97,05 \%$ & $97,05 \%$ & $97,05 \%$ & $97,05 \%$ \\
\hline $\begin{array}{l}\text { Menor limite de } \\
\text { confiança }\end{array}$ & 6,62 & 4,13 & 23,9 & 17,1 & 31,5 & 0,77 \\
\hline $\begin{array}{c}\text { Menor limite de } \\
\text { confiança }\end{array}$ & 6,97 & 4,28 & 31,3 & 24,8 & 36,8 & 0,86 \\
\hline \multicolumn{7}{|l|}{$\begin{array}{c}\text { Teste de Shapiro } \\
\text { Wilk }\end{array}$} \\
\hline Valor de $p$ & 0,1871 & 0,4422 & 0,0001 & $<0,0001$ & 0,0837 & 0,3929 \\
\hline
\end{tabular}


Para comparação entre grupos, no tocante à idade, os animais foram divididos em: idade inferior a seis anos $(n=43)$ e idade superior a seis anos $(n=26)$. Assim, cada variável analisada, de ambos os grupos, passou pelo teste de normalidade de Shapiro-Wilk e teste $\mathrm{F}$ para comparação de suas variâncias. Para aqueles com características de distribuição paramétrica não pareados utilizou-se o teste $\mathrm{T}$, e naqueles com características não-paramétricas utilizou-se o teste de Mann-Whitney.

Dos parâmetros avaliados somente monócitos, plaquetas, albumina, proteína total, ALT e ureia obtiveram resultados com relevância estatística $(p<0,05)$. Dentre estes, o teste $t$ foi utilizado para avaliar os parâmetros: monócitos $(p<0,0032)$, plaquetas $(p<0,0155)$ e albumina $(p<0,0479)$, e o teste de Mann-Whitney os parâmetros proteína total $(p<0,0008)$, ALT $(p<0,0459)$ e ureia $(p<0,0210)$. Para melhor observação dos dados, realizaram-se gráficos boxplot para as variáveis com significância estatística (Gráfico 3).

A variável sexo também foi avaliada, sendo que a comparação entre machos ( $n=28)$ e fêmeas ( $n=41)$ também foi submetida ao teste de normalidade Shapiro-Wilk e comparação entre as variâncias pelo teste $F$, determinando-se, assim, as distribuições dos dados e o teste a ser escolhido. No que se diz respeito às variáveis estudadas, não foi encontrada relevância estatística em nenhuma delas $(p<0,05)$. 

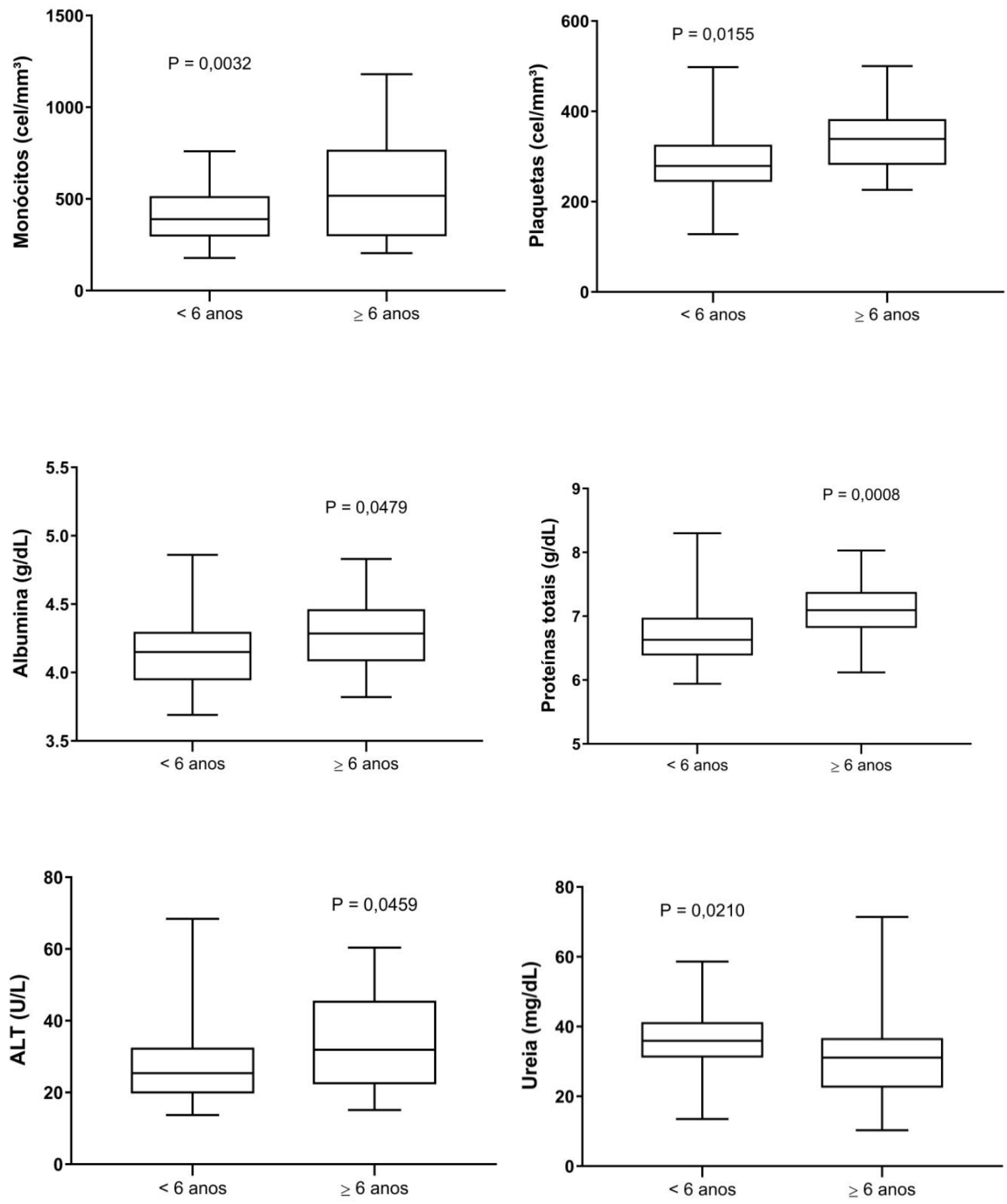

Gráfico 3. Representação gráfica no formato boxplot do grupo idade com relevância estatística $(p<0,05)$ de cães adultos da raça Dachshund. São Paulo, 2017. 
Nota: Para análise utilizou-se teste t não pareado (monócitos, plaquetas e albumina) e teste de MannWhitney (proteínas totais, ALT e ureia). Serviço de Laboratório Clínico, HOVET-FMVZ-USP, 2017. 


\section{DISCUSSÃO}

A variabilidade racial já é difusamente estudada e avaliada no que se diz respeito aos exames laboratoriais e suas especificidades. Assim como as demais raças, o Dachshund possui características próprias e peculiares e, dessa forma, foi escolhido para avaliação dos parâmetros hematológicos e bioquímicos. Os valores obtidos do cão adulto e sadio servem como modelo para poder detectar qualquer evidência de insalubridade na população. Assim sendo, os valores obtidos de cães adultos e sadios da raça Dachshund foram avaliados para observar suas particularidades e padrão de normalidade da raça. $\mathrm{Na}$ tabela a seguir, simulou-se uma possível realidade na clínica médica, colocando-se os valores obtidos dos cães adultos e sadios da raça Dachshund e os valores de referência postulados pelo Serviço de Laboratório Clínico, do Departamento de Clínica Médica do HOVETFMVZ-USP (Tabela 7).

Tabela 7. Valores hematológicos e bioquímicos de cães adultos e sadios da raça Dachshund e intervalo de referência do Serviço de Laboratório Clínico, VCM-HOVET-FMVZ-USP

\begin{tabular}{ccc}
\hline & Dachshund & Referência \\
\hline Eritograma & & \\
\hline Hemácias & $8,2 \times 10^{6} / \mu \mathrm{L} \pm 0,74$ & $5,0-8,0 \times 1010^{6} / \mu \mathrm{L}$ \\
Hemoglobina & $18,98 \mathrm{~g} / \mathrm{dL} \pm 1,60$ & $12,0-18,0 \mathrm{~g} / \mathrm{dL}$ \\
Hematócrito & $55 \% \pm 5,0$ & $37-57 \%$ \\
VCM & $66,2 \mathrm{fL} \pm 2,71$ & $60,0-77,0 \mathrm{fL}$ \\
HCM & $23 \mathrm{pg}, \mathrm{P} 25-75,22-24$ & $22,0-27,0 \mathrm{pg}$ \\
CHCM & $35 \%, \mathrm{P} 25-75,34-35,05$ & $31,0-36,0 \%$ \\
\hline Leucograma & $9119 \mu / \mathrm{L} \pm 2402$ & \\
\hline Leucócitos totais & $6080 \mu / \mathrm{L}, \mathrm{P} 25-75,4942-7657$ & $3.000-11.800 / \mathrm{uL}$ \\
Neutrófilos segmentados & $1730 \mu / \mathrm{L}, \mathrm{P} 25-75,1371-2275$ & $1.500 / 5.000 / \mathrm{uL}$ \\
Linfócitos & $430 \mu / \mathrm{L}, \mathrm{P} 25-75,303-595$ & $0-800 / \mathrm{uL}$ \\
Monócitos & $230 \mu / \mathrm{L}, \mathrm{P} 25-75,171-430$ & $0-1.300 / \mathrm{uL}$ \\
Eosinófilos & $0 \mu / \mathrm{L}, \mathrm{P} 25-75,0-60$ & $0-140 / \mathrm{uL}$ \\
Basófilos & & $200-600 \times 10^{3} / \mu \mathrm{L}$ \\
\hline
\end{tabular}




\begin{tabular}{ccc}
\hline Perfil Hepático & \\
\hline Proteína total & $6,86 \mathrm{~g} / \mathrm{dL} \pm 0,50$ & $5,3-7,6 \mathrm{~g} / \mathrm{dL}$ \\
Albumina & $4,19 \mathrm{~g} / \mathrm{dL} \pm 0,26$ & $2,3-3,8 \mathrm{~g} / \mathrm{dL}$ \\
ALT & $26,9 \mathrm{U} / \mathrm{L}, \mathrm{P} 25-75,21,5-34,4$ & $10-88 \mathrm{U} / \mathrm{L}$ \\
FA & $20,5 \mathrm{U} / \mathrm{L}, \mathrm{P} 25-75,14-28,1$ & $20-150 \mathrm{U} / \mathrm{L}$ \\
\hline Perfil Renal & & \\
\hline Ureia & $34,59 \mathrm{mg} / \mathrm{dL} \pm 10,36$ & $20-40 \mathrm{mg} / \mathrm{dL}$ \\
Creatinina & $0,82 \mathrm{mg} / \mathrm{dL} \pm 0,12$ & $0,7-1,4 \mathrm{mg} / \mathrm{dL}$ \\
\hline
\end{tabular}

Nota: Para os dados de tendência central e dispersão, utilizaram-se os dados com distribuição gaussiana, a média e o desvio padrão, e para os dados não-gaussianos, a mediana e os intervalos interquartis.

Os valores de hemácias e hemoglobina estão acima dos valores de referência para a espécie, assim como, o valor de albumina. Mas também não se pode deixar de notar que os valores de hematócrito, VCM e ureia estão tendendo ao limite superior de normalidade. Tais achados corroboram com os encontrados por Torres et al. (2015), estudo em que foram comparadas 61 amostras hematológicas de Dachshunds com de 60 de cães sem definição racial, e concluíram que, o hematócrito obteve valor de $52 \%$ contra $50 \%$, a contagem de hemácias $7,7 \times 10^{6} \mathrm{u} / \mathrm{L}$ contra $7,1 \times 10^{6} \mathrm{u} / \mathrm{L}$ e concentração de hemoglobina $18,2 \mathrm{~g} / \mathrm{dL}$ contra $16,8 \mathrm{~g} / \mathrm{dL}$, respectivamente, nos Dachshunds e nos cães sem definição racial. Os demais analitos não mostraram diferença estatística entre os dois grupos de cães avaliados. Os valores de hematócrito, contagem global de hemácias e concentração de hemoglobina do presente estudo mostraram-se superiores aos observados por Torres et al. (2015), confirmando assim os valores diferenciados dos referidos parâmetros hematológicos para cães adultos da raça Dachshund. A explicação para tal seria devido à origem da raça Dachshund, por se tratar de uma raça condrodistrófica e ter sido geneticamente selecionada para caça subterrânea, em locais com baixa tensão de oxigênio, incitando uma adaptação ao longo de tempo e refletindo nos valores de hemácias, hematócrito e hemoglobina (TORRES et al., 2015), diferentemente da hipótese proposta de que haveria uma contração esplênica em momentos de estresse contribuindo para uma secreção inapropriada de eritropoetina devido à diminuição de oxigenação dos tecidos (JAIN, 1993). A coleta de sangue dos animais deste projeto foi realizada mediante contenção e punção de 
veia jugular, após outros procedimentos, como realização de radiografia torácica, aferição de pressão arterial e realização de eletrocardiograma, havendo tempo suficiente para a ambientação do animal. Alguns desses animais, já se apresentavam confortáveis ao ambiente hospitalar, não apresentando nenhum sinal de estresse aparente, e mesmo aqueles que de alguma forma apresentaram algum sinal de estresse a avaliação do hemograma não demonstrou o clássico leucograma de estresse (HARVEY, 2012).

Outras raças também já foram estudadas, tais quais: o Dogue de Bordeaux é uma raça que também já foi avaliada e possui um intervalo de referência próprio, estudado pelo grupo de Lavoué et al. (2013), que observaram diferenças, com relevância clínica, nos seguintes analitos: proteína total, ALT, AST, colesterol, lípase, tiroxina e a raça Greyhound, na qual as alterações encontradas nos intervalos de referência são creditadas à seleção genética da raça para capacidade de corrida e, consequentemente, melhor capacidade de transporte de oxigênio (ZALDIVARLOPEZ et al., 2011)

Outro analito analisado, que comparado com intervalo de referência, obteve valor acima foi a albumina, com o valor médio de 4,19 g/dL $\pm 0,26$ e 2,3-3,8 g/dL, respectivamente. A massa muscular é resultado da regulação entre catabolismo e síntese proteica. Sendo assim, a albumina é a proteína mais abundante do plasma, e esta participa de forma direta para aumento da massa muscular e manutenção da mesma a longo prazo (STOCKHAM; SCOTT, 2011). Em medicina humana, o estudo realizado por Vaz et al.(2016) associou a baixa concentração de proteínas com a sarcopenia em idosos, tornando importante o consumo adequado de proteínas para manutenção da massa muscular ao longo dos anos, embora os estudos nessa área sejam escassos. Com essas informações e buscando uma justificativa para tal analito (albumina) apresentar valor maior, nos Dachshunds, que os de referência para espécie canina, pode-se atribuir tal fato, mais uma vez, à conformação da raça. Segundo a Confederação Brasileira de Cinofilia (http://www.cbkc.com.br/padroes/pdf/grupo4/dachshund.pdf; consulta em 10 de Maio de 2016) e a Enciclopédia do Cão (2011), os Dachshunds apresentam corpo longo com membros curtos, arqueados e musculosos, musculatura esta desenvolvida que poderia explicar o valor encontrado de albumina. Outra possível explicação poderia ser creditada aos resultados obtidos por Jensen et al. (1994) que observaram 
valores elevados de creatinina, quando o sangue era coletado da veia jugular e comparados com sangue coletado de veia cefálica, sendo que relataram que a $\mathrm{v}$. jugular recebe mais sangue venoso proveniente de origem muscular esquelética, em comparação à v. jugular. Dessa forma, a albumina poderia estar em valor elevado devido tal hipótese, uma vez que, todas as coletas foram realizadas na veia jugular. Entretanto, faz-se necessária comparação dos valores ora obtidos com os de sangue coletados na de veia cefálica para constatar tal afirmação.

Para comparação entre grupos da variável idade, os animais foram divididos em dois : com idade inferior a seis anos de idade e superior de seis anos de idade. Dos analitos avaliados, monócitos, plaquetas e proteínas totais obtiveram valores maiores no grupo de idade superior a seis anos, ou seja, com a idade tais valores aumentam seus níveis séricos. Como afirmado por Lawrence et al. (2013), a explicação para tais resultados é que, com o avançar da idade, os animais são mais propensos a adquirir doenças inflamatórias que causam aumento de células ligadas ao processo inflamatório, como monócitos, plaquetas, bem como de proteínas totais, processo esse denominado inflammaging. Animais com idade superior a 10 anos não foram estudados no presente trabalho, devido à exclusão de comorbidades, mais frequentes em animais mais idosos. A enzima ALT e a albumina também revelaram valores elevados no grupo superior a seis anos de idade e, segundo Zaldivar-Lopez et al. (2011) que estudaram a raça a Greyhound, valores elevados de creatinina e ALT foram observados com o decorrer da idade, fatos creditados à grande massa muscular dessa raça, resultando em maiores atividades séricas das referidas enzimas sem, necessariamente, indicar algum estado patológico. Da mesma forma, o Dachshund também apresenta corpo longo com membros curtos, arqueados e musculosos, e os resultados relativos à albumina e ALT, que se revelaram elevados nesses animais, podem ser justificados para manutenção da musculatura, ao longo do desenvolvimento do animal. No que se diz respeito à ureia, a comparação dos grupos revelou diminuição dos níveis séricos no grupo com idade superior a seis anos, fato que pode estar relacionado às mudanças de ingestão proteica com o decorrer dos anos; já o aumento de ureia ocorreria após os 10 anos de idade, devido condições de desidratação ou declínio da função renal com o avançar da idade (CHANG et al., 2016). O declínio da ureia sérica, segundo Lawrence et al. (2013), corrobora com o encontrado neste estudo, mas a faixa etária 
exata em que ocorre aumento desse analito requer estudos com animais com idade superior a 10 anos.

Outros analitos do exame bioquímico também já foram bastante estudados como os níveis de cálcio, fósforo e fosfatase alcalina (FA), que foram mais elevados em cães mais jovens, o que reflete o aumento da concentração de hormônio do crescimento na maturação óssea e reabsorção renal de fósforo, fato que ocorre até dois a quatro anos idade. A creatinina sérica revelou aumento e posterior diminuição com a idade, o que seria decorrente do aumento da massa muscular, até a maturidade, e posterior sarcopenia relacionada à idade (CHANG et al., 2016). Não houve diferença estatística, segundo os dois grupos estudados, para os analitos FA e creatinina, o que impede qualquer afirmação, pois animais menores que 12 meses de idade não foram incluídos no trabalho. Ainda, em relação aos exames bioquímicos e a importância da padronização racial e o auxílio que o mesmo contribui na rotina clínica, o estudo realizado por Fernandez et al. (2006), comparou cães da raça Golden Retriever com distrofia muscular Duchenne "like" com cães normais da mesma raça, e o resultado foi de que os níveis de AST, ALT e CK foram, respectivamente, 15, 22 e 70 vezes maiores nos animais com distrofia Duchenne "like" do que nos normais.

Os resultados obtidos foram comparados, segundo sexo, não sendo encontrada diferença estatística em nenhum dos analitos estudados, contrariamente ao observado em estudos já publicados, a exemplo daquele realizado por Chang et al. (2016), no qual os níveis séricos de proteína total, globulina e creatinina foram maiores em machos e, devidamente, explicados pela conformação muscular do macho em comparação à das fêmeas.

Por fim, outro dado interessante encontrado na literatura foi de que cães castrados apresentam menores variações nos valores de HCM, CHCM e hemoglobina no decorrer dos anos. Segundo Lawrence et al. (2013), concentrações fisiológicas de hormônios sexuais podem ter algum envolvimento na eritropoiese em cães, pois cães castrados apresentam valores aumentados de hemoglobina $(\mathrm{Hb})$, hemoglobina corpuscular média (HCM) e CHCM do que aqueles não castrados. No presente estudo, não foi possível realizar tal comparação desde que a maioria dos 69 animais estudados era esterilizada. 


\section{CONCLUSÕES}

Os resultados encontrados no presente trabalho corroboram com os da literatura e validam a hipótese inicial de que intervalos de referência divergem nas diferentes raças existentes. A raça Dachshund, por apresentar peculiaridades na conformação corporal e na sua origem, revelou parâmetros hematológicos e bioquímicos diferentes quando comparados com intervalos de referência já estabelecidos para a espécie canina. Dentre eles, hematócrito, hemoglobina e albumina podem ser explicados devido à raça ter sido desenvolvida para caça subterrânea, local com baixa tensão de oxigênio, e com conformação muscular robusta.

Tais achados confirmam a necessidade de conhecer os valores de intervalo de referência para cada raça e suas particularidades, isentando clínicos de qualquer interpretação errônea desses parâmetros e colaborando, assim, de uma maneira mais exata no diagnóstico clínico. 


\section{REFERÊNCIAS}

CAMPORA, C.; FREEMAN, K.P.; LEWIS, F.I.; GIBSON, G.; SACCHINI, F.; SANCHEZ-VAZQUEZ, M.J. Determination of haematological reference intervals in healthy adult greyhounds. Journal of Small Animal Practice. 52:301-309, 2011

CHANG, Y.M.; HADOX, E; SZLADOVITS, B.; GARDEN, O.A. Serum biochemical phenotypes in the domestic dog. PLos One. 11(2): e149650, 2016.

CAR, B.D. The hematopoietic system. In: WEISS, D.J; WARDROP, K.J. Veterinary Hematology. Wiley-Blackwell. 6d, p27-35, 2010.

FERNANDEZ, E.L.; PEREIRA, R.C.; SANTOS, A.L.F.; YAMAKI, F.L.; LARSSON, M.H.M.A. Padronização dos parâmetros bioquímicos de cães da raça Golden Retriever. IN:XVII CONGRESSO ESTADUAL DE MEDICINA VETERINÁRIA-RS. Gramado, 2006.

FETTMAN, M.J; REBAR, A. Laboratory evaluation of renal function. In: THRALL, M.A. Veterinary Hematology and Clinical Chemistry. Blackwell Ed, p301-328, 2006.

FRIEDRICHS, K.R; HARR, K.E; FREEMAN, K.P; SZLADOVITS, B; WALTON, R.M;BARNHART, K.F;BLANCO-CHAVEZ, J. ASCVP reference interval guidelines: determination of de novo reference intervals in veterinary species and other related topics. Veterinary Clinical Pathology .41(4): 441-453, 2012.

GEFFRE, A; BRAUN, J.P; TRUMEL, C; CONCORDET, D. Estimation of reference intervals from small samples: an example using canine plasma creatinine. Veterinary Clinical Pathology. 38 (4): 477-484, 2009.

GOUGH, A.; THOMAS, A. Breed predispositions to disease in dogs and cats. 2 . ed. Chichester: Wiley-Blackwell, 2010. 
GRÄSBECK, R; SARIS, N.E. Establishment and use of normal values.

Scandinavian Journal of Clinical and Laboratorial Investigation. 26: 62-63, 1969.

HARPER, E.J.; HACKETT, R.M; WILKINSON, J; HEATON, P.R. Age-related variations in hematologic and plasma biochemical test results in Beagles and Labrador Retrievers. Journal of the American Veterinary Medical Association. 223(10) 1436-1442, 2003

HARVEY, J.W. Veterinary Hematology : A diagnostic guide and color atlas. Elsevier Saunders, 2012.

JAIN, C.N. Essentials of Veterinary Hematology. Lea ; Febiger. 5Ed.1993.

JENSEN, A.L; WENCK, A; KOCH, J; POULSEN, J.S.D; Comparison of results oh haematological and clinical chemical analyses of blood samples obtained from the cephalic and external jugular veins in dogs. Research in Veterinary Science. 56, 24-29, 1994.

JUNQUEIRA, L.C; CARNEIRO, J. Histologia Básica. 10ed. Ed. Guanabara Koogan, p.407-414, 2004.

LASSEN, E.D. Perspective in data interpretation. In: THRALL, M.A. Veterinary Hematology and Clinical Chemistry. Blackwell Ed, p45-53, 2006.

LASSEN, E.D. Laboratory evaluation of the liver THRALL, M.A. Veterinary Hematology and Clinical Chemistry. Blackwell Ed, p355-375, 2006.

LAWRENCE, J; CHANG, Y.M.R; SZLADOVITS, B; DAVISON, L.J; GARDEN, O.A. Breed-Specific Hematological Phenotypes in the Dog: A Natural Resource for the Genetic Dissection of Hematological Parameters in a Mammalian Species. PLos One. 8(11): e81288, 2013. 
LAVOUÉ, R; GEFFRÉ,A; BRAUN, J.P; PEETERS, D; TRUMMEL, C. Breed-specific biochemical reference intervals for the adult Dogue de Bordeaux. Veterinary Clinical Pathology. 42(3): 346-359, 2013.

LINDBLAD-TOH, K; WADE, C.M; MIKKELSEN, T. S; KARLSSON, E.K; JAFFE, D.B; KAMAL, M; CLAMP, M; CHANG, J. L; KULBOKAS III, E. J; ZODY, M.C; MAUCELI, E; XIE, X; BREEN, M; WAYNE, R.K; OSTRANDER, E.A; PONTING, C.P; GALIBERT, F; SMITH, D.R; JONG, P.J; KIRKNESS, E; ALVAREZ, P; BIAGI, T; BROCKMAN, W; BUTLER, J; CHIN, C.W; COOK, A; CUFF, J; DALY, M.J; DECAPRIO, D; GNERRE, S; GRABHERR, M; KELLIS, M; KLEBER, M; BARDELEBEN, C; GOODSTADT, L; HEGER, A; HITTE, C; KIM, L; Koepfli, K.P; PARKER, H.G; POLLINGER, J.P; SEARLE, S.M.J; SUTTER, N.B; THOMAS, R; WEBBER, C; Broad Institute Genome Sequencing Platform; LANDER, E.S. Genome sequence, comparative analysis and haplotype structure of the domestic dog. Nature. 438 (8), 803-819, 2005.

NIELSEN, L; KJELGAARD-HANSEN, M; JENSEN, A.L; KRISTENSEN A.T. Breedspecific variation of hematologic and biochemical analytes in healthy adult Bernese Mountain dogs. Veterinary Clinical Patholology. 39:20-28, 2010.

OLVER, C.S. Erythropoiesis. In: WEISS, D.J; WARDROP, K.J. Veterinary Hematology. Wiley-Blackwell. 6d, p36-42, 2010.

PARKER, B.N.J; BLOWEY, R.W. A comparison of blood from the jugular vein and coccygeal artery and veins of cows. Veterinary Record. 95, 14-18, 1974.

PEDERSEN, H.D; HÄGGSTRÖM, J; OLSEN, L.H; CHRISTENSEN, K; SELLIN, A; BURMEISTER, M.L; LARSEN, H. Idiopathic Asymptomatic Thrombocytopenia in Cavalier King Charles Spaniels Is an Autosomal Recessive Trait. Journal of Veterinary Internal Medicine. 16(2): 169-173, 2002.

PORTER, J.A; CANADAY, W.R. Hematologic values in mongrel and greyhound dogs being screened for research use. Journal of the American Veterinary Medical Association.159:1603-1606,1971. 
RAUTENBACH, G.H; BOOTH, C; HÖHN, E.W. A comparison of health parameters in two different canine populations. Part 1: Haematological data. Journal of the South African Veterinary Association. 58 (4): 179-182, 1987.

RAUTENBACH, G.H; JOUBERT, H.F. A comparison of health parameters in two different canine populations. Part 2: Chemical pathology data. Journal of the South African Veterinary Association. 59 (3): 135-138, 1988.

ROSSET, E; RANNOU, B;CASSELEUX, G; CHALVET-MONFREY,K; BUFF, S. Agerelated changes in biochemical and hematologic variables in Borzoi and Beagle puppies from birth to 8 weeks. Veterinary Clinical Patholology. 41(2): 272-282, 2012.

SHARKEY, L; GJEVRE, K; HEGSTAD-DAVIES, R; TORRES, S; MUÑOZ-ZANZI, C. Breed-associated variability in serum biochemical analytes in four large-breed dogs. Veterinary Clinical Pathology. 38:375-380,2009.

SHIEL, R. E; BRENNAN, S. F; O'ROURKE, L. G.; MCCULLOUGH, M; MOONEY, C. $T$. Hematological values in young pretraining healthy greyhounds. Veterinary Clinical Pathology. 36, 274-277, 2007.

STOCKHAM, S. L; SCOTT, M.A. Fundamentos de Patologia Clínica Veterinária. Guanabara Koogan, 2Ed, 2011.

SULLIVAN, P.S; EVANS, H.L; MCDONALD, T.P. Platelet concentration and hemoglobin function in greyhounds. Journal of the American Veterinary Medical Association. 205:838-841,1994.

THRALL, M.A. Erythrocyte morphology. In: THRALL, M.A. Veterinary Hematology and Clinical Chemistry. Blackwell Ed, p69-82, 2006.

TORRES, A.R.; CASSLE, S.E. HAYMORE, M.; HILL, R.C. Hematologic differences between Dachshunds and mixed breed dogs. Veterinary Clinica Pathology .43, 519-524, 2015. 
WALTON, R.M. Subject-based reference values: biological variation, individuality, and reference change values. Veterinary Clinical Pathology. 41(2), 175-181, 2012.

WEISER, G. Sample collection, processing, and analysis of laboratory service options. In: THRALL, M.A. Veterinary Hematology and Clinical Chemistry. Blackwell Ed, p39-44, 2006.

ZALDIVAR-LOPEZ, S; MARIN, L.M; LAZBIK, M.C; WESTENDORF- STINGLE, N; HENSLEY, S; COUTO, C.G. Clinical pathology of Greyhounds and other sighthounds. Veterinary Clinical Pathology. 40:414-425,2011. 


\section{APÊNDICES}

APÊNDICE A - Termo de consentimento entregue para os proprietários assinarem - São Paulo/2017

TERMO DE CONSENTIMENTO LIVRE E ESCLARECIDO

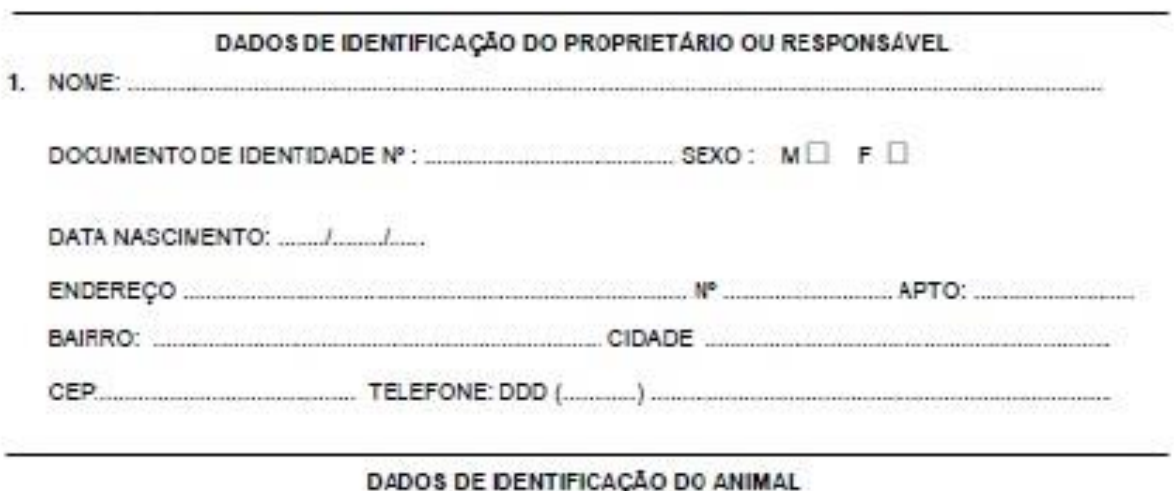

2. NONE DO ANMAL EIOU NUMERO DE REGISTRO (TATUAGEM, MICROCHIP, BRNCO)

ESPECIE:
SEXO
(PARA REBANHOS)
IDENTIFICAÇÅO DO LOTE:

DADOS SOBREA PESQUISA

3. TITULO DO PROTOCOLO DE PESQUISA Padronizaçăo de paranetros ecocardlogrăcos, elejocardiograficos, raclograflcos, laboratorials e pressăo arterial sistollca pelo metodo Doppler em cales da raça Dachshund

PESQUISADOR: M.V. Ms. Paula Hromi tikava / Prota. Dra. Marla Helena Matiko Akao Larsson

CARGOIFUNCAO:POs-graduandaProtessora ttular INSCRICÅO CONSELHO REGIONAL N 20174-SP/796-SP

4. Departamento: VCM SErviço: CARDIOLOGIA

5. AVALIAÇAO DO RISCO DA PESCUISA:

$\begin{array}{ll}\text { RISCO MINIMOX } & \text { RISCO NEDIO } \square \\ \text { RISCO BAIXO } \square & \text { RISCO MAIOR } \square\end{array}$

6. DURAÇAO DAPESQUISA : 1 ano 
FACULDADE DE MEDICINA VETERINÁRIA E ZOOTECNIA DA UNIVERSIDADE DE SÄO PAULO

1 - 0 estudo tem como objetivos padronizar paränetros ecocardiográficos, eletrocardiográficos, radiográícos e a pressão arterial sistémica pelo mébodo Doppler em cáes addultos e sadios da raça Dachshund dos tamanhos standard, miniatura e kanichen;

2 - Os animais juntamente com seus proprietános serão encaminhados ao Serviço de Carciologia para realizaçảo dos exames de mensuraçăo da PAS pelo método Doppler, exame ecocardiográfico. exame eletrocardiográfico, exame físico e coleta de sangue. Os animais também serão encaminhados ao Serviço de Diagnóstico por Imagem no Departamento de Cirurga/HOVET FMVZUSP para a realizaçăo das radiografias torácicas.

3 - Serăo realizados anamnese, mensuração da PAS pello método Doppler, exame ecocardicgráfico, exame eletrocardiográfico, radiografia torácica, exame fisico e coleta de sangue para a realizaçâo dos seguintes exames: henograma compleb, perfl renal, perfl hepático e glicenia.

4 - O desconforto do animal será o de permanecer nas posições necessárias para a realizaçăo dos exames, sem o uso de sedaçäo e serăo cortidos pelos proprietários;

5 - Trata-se de estudo experimental testando a hipótese de que os cães da raça Dachshund devido a acondroplasia / hpocondroplasia, possuam valores ecocardiográficos e de VHS diferenciados;

6 - Năo há procedimentos altemativos que possam ser vantajosos;

7 - Garantia de acesso: em qualquer éapa do estudo, vocè terá acesso aos profissionais responsáveis pela pesquiss para esclarecimento de eventuais dividas. O principal investgador é a M.V. Ms. Paula Hromi ltikawa que pode ser encontrada na Av. Dr. Oriando Marques de Paiva, 87 - Cidade Universiária - Säo Paulo - SP - Hospital Veterinário da Universidade de Säo Paulo - Serviço de Cardiologia. Telefone 3091-1261.

8 - É garantida a liberdade da retirada de consentimento a qualquer momento e deixar de participar do estudo, sem qualquer prejuizo à continuidade de tratamento do animal na Instituiçâo;

8 - Direito de confidencialidade - As informậ̣es obtidas (relativas tarto ao proprietário quanto ao animal) serão analiadas em conjunto com outros pacientes, nâo sendo divulgado a identificaçäı de nenhum animal ou propriéário;

10 - Compromisso do pesquisador de utilizar os dados, e o material coletado somente para esta pesquisa ou após a aprovação da CEUAVET.

Acredito ter sido suficientemente informado a respeito das informaçóes que li ou que foram lidas para mim, descrevendo o estudo" Nensuraçáo da pressăo arterial sistêmica pelo método Doppler em cäes da raça Dachshund em três posiçoies anatómicas" 
Eu ciscuti com o Dr. M.V. Mestre Paula Hiromi ltikawa. sobre a minha decisão en incluir meu(s) animal(is) nesse estudo. Ficaram claros para mim quais são os propósitos do estudo, os procedimentos a serem realizados en meu(s) animal(is), seus cesconfortos e riscos, as garantias de confidencialidade e de esclarecimentos permanentes.

Concordo voluntariamente que meu(s) animal(s) particpe(m) deste estudo e poderei retirar o meu consentimento a qualquer momento, antes ou durante o mesmo, sem penalidades ou prejuízo ou perda de qualquer beneficio que eu ou meu(s) animal(is) possa(m) ter adquirido, ou no meu atendimento neste Serviço.

Nome e assinatura do proprietánio ou responsável

(caso seja o responsável, descrever o vihculo)

Dara

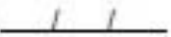

Nome e assinatura da testemurha

Daka

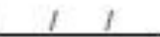

para casos de proprietários analfabetos, semi-analfabetos ou portadores de deficiência auditiva ou visual.

\section{(Somente para o responsável do projeto)}

Declaro que obtive de forma apropriada e voluntária o Consentimento Livre e Esclarecido deste propietário para a paricipaçăo de seu(s) animal(s) neste estudo.

Nome e assinatura do responsável pelo estudo

Data

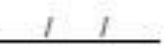


APÊNDICE B - Folder publicado nas redes sociais Facebook e Whatsapp e distribuídos em diversos locais da FMVZ-USP- São Palo/2017

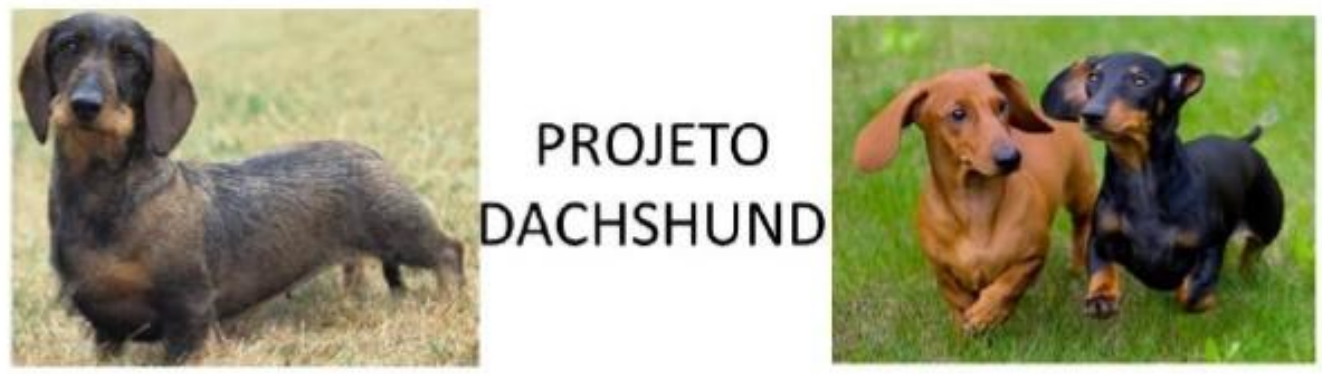

Selecionam-se cães adultos (entre 18 meses e 10 anos) e sadios da raça Dachshund de todos os portes para avaliação (check-up) cardiológico. Local: Hospital Veterinario da USP Inscriçăo triagem: cardiovetusp@gmail.com ou Cel.: 9-4325-8406 (via Whatsapp)

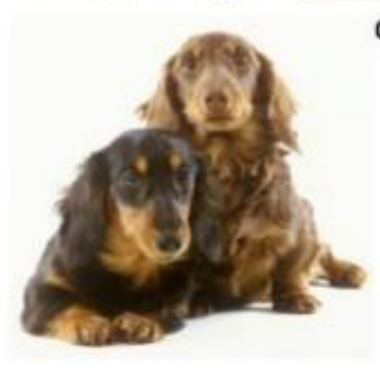

Os exames do projeto são gratuitos

Cães da raça Dachshund também são conhecidos como: Salsicha, Dach, Cofap, Bassete Teckel

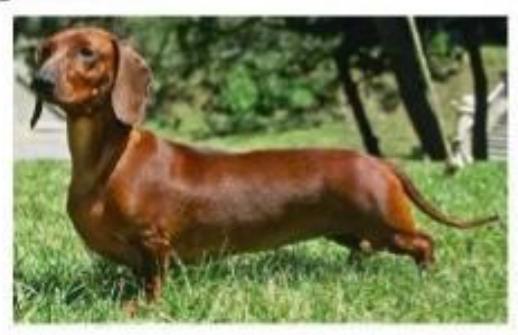


APÊNDICE C - Parâmetros de eritrograma de 69 cães adultos e sadios da raça Dachshund - São Paulo/2017

\begin{tabular}{|c|c|c|c|c|c|c|}
\hline Número & $\begin{array}{c}\mathrm{He} \\
\left(\mathrm{milh} / \mathrm{mm}^{3}\right)\end{array}$ & $\begin{array}{c}\mathrm{Hb} \\
(\mathrm{g} \%)\end{array}$ & Ht (\%) & $\begin{array}{c}\text { VCM } \\
\text { (fl) }\end{array}$ & $\begin{array}{c}\mathrm{HCM} \\
(\mathrm{pg})\end{array}$ & $\begin{array}{c}\mathrm{CHCM} \\
(\%)\end{array}$ \\
\hline 1 & 7,9 & 18,7 & 54 & 69 & 24 & 34 \\
\hline 2 & 7,9 & 18,9 & 55 & 70 & 24 & 34 \\
\hline 3 & 6,8 & 15,9 & 45 & 66 & 23 & 35 \\
\hline 4 & 8,3 & 19,3 & 56 & 67 & 23 & 34 \\
\hline 5 & 8,5 & 19 & 54 & 64 & 22 & 35 \\
\hline 6 & 9 & 20,8 & 59 & 65 & 23 & 35 \\
\hline 7 & 7,7 & 18,7 & 54 & 70 & 24 & 35 \\
\hline 8 & 9 & 20,2 & 59 & 66 & 22 & 34 \\
\hline 9 & 8 & 18,7 & 53 & 66 & 23 & 35 \\
\hline 10 & 8,3 & 19,6 & 57 & 68 & 24 & 40 \\
\hline 11 & 7,5 & 18 & 51 & 68 & 24 & 35 \\
\hline 12 & 8,7 & 19,2 & 59 & 67 & 22 & 33 \\
\hline 13 & 8,5 & 18,6 & 55 & 64 & 22 & 34 \\
\hline 14 & 9,1 & 19,9 & 59 & 65 & 22 & 34 \\
\hline 15 & 8,9 & 20,5 & 61 & 69 & 23 & 33 \\
\hline 16 & 8,7 & 19,7 & 58 & 67 & 23 & 34 \\
\hline 17 & 7,9 & 20,4 & 58 & 73 & 26 & 35 \\
\hline 18 & 8,5 & 18,9 & 57 & 67 & 22 & 33 \\
\hline 19 & 9,3 & 19,9 & 60 & 65 & 21 & 33 \\
\hline 20 & 7,9 & 19,1 & 54 & 69 & 24 & 35 \\
\hline 21 & 8,6 & 21 & 60 & 69 & 24 & 35 \\
\hline 22 & 8,5 & 19,7 & 58 & 69 & 23 & 34 \\
\hline 23 & 8,7 & 20,3 & 57 & 66 & 23 & 36 \\
\hline 24 & 9,12 & 21 & 60,9 & 67 & 23,1 & 34,6 \\
\hline 25 & 9,3 & 21,3 & 63 & 67 & 23 & 34 \\
\hline 26 & 8,3 & 19,1 & 55 & 66 & 23 & 35 \\
\hline 27 & 8,2 & 18,6 & 55 & 67 & 23 & 34 \\
\hline 28 & 8,9 & 21,3 & 63 & 70 & 24 & 34 \\
\hline 29 & 8,3 & 18,3 & 54 & 65 & 22 & 34 \\
\hline 30 & 7,2 & 16,2 & 45,7 & 63,5 & 22,5 & 35,4 \\
\hline 31 & 9,34 & 21,5 & 61,1 & 65,4 & 23 & 35,2 \\
\hline 32 & 7,17 & 16,8 & 47,5 & 66,2 & 23,4 & 35,4 \\
\hline 33 & 8,22 & 19,2 & 55,4 & 67,5 & 23,4 & 34,6 \\
\hline 34 & 7,5 & 18,3 & 50 & 66,6 & 24,4 & 36,7 \\
\hline 35 & 7,85 & 18,3 & 51,1 & 65,1 & 23,3 & 35,7 \\
\hline 36 & 8,3 & 20 & 56 & 67 & 24 & 36 \\
\hline 37 & 8,36 & 19,4 & 54,7 & 65,4 & 23,2 & 35,5 \\
\hline 38 & 9,4 & 22,4 & 64 & 68 & 24 & 35 \\
\hline 39 & 8,1 & 18,2 & 52 & 64 & 22 & 35 \\
\hline 40 & 6,9 & 15,3 & 43 & 62 & 22 & 35 \\
\hline
\end{tabular}




\begin{tabular}{lcccccc}
\hline $\mathbf{4 1}$ & 7,4 & 18,1 & 50 & 67 & 24 & 36 \\
$\mathbf{4 2}$ & 9,3 & 20,8 & 59 & 63 & 22 & 36 \\
$\mathbf{4 3}$ & 6,9 & 18 & 50 & 72 & 26 & 36 \\
$\mathbf{4 4}$ & 8,2 & 19,2 & 57 & 69 & 24 & 34 \\
$\mathbf{4 5}$ & 7 & 16,8 & 50 & 71 & 24 & 34 \\
$\mathbf{4 6}$ & 8,5 & 20,6 & 61 & 72 & 24 & 34 \\
$\mathbf{4 7}$ & 8 & 19,4 & 56 & 70 & 24 & 35 \\
$\mathbf{4 8}$ & 9,9 & 21,6 & 65 & 65 & 22 & 33 \\
$\mathbf{4 9}$ & 7 & 15,8 & 46 & 66 & 22 & 34 \\
$\mathbf{5 0}$ & 9,4 & 20,8 & 60 & 64 & 22 & 35 \\
$\mathbf{5 1}$ & 7,7 & 16,4 & 47 & 61 & 21 & 35 \\
$\mathbf{5 2}$ & 9,1 & 20 & 57 & 63 & 22 & 35 \\
$\mathbf{5 3}$ & 7,91 & 18,1 & 52,6 & 66,4 & 22,9 & 34,5 \\
$\mathbf{5 4}$ & 7,24 & 16,6 & 47,1 & 65,1 & 23 & 35,3 \\
$\mathbf{5 5}$ & 8,22 & 18 & 51,3 & 62,4 & 21,9 & 35,1 \\
$\mathbf{5 6}$ & 7,81 & 18,7 & 52,8 & 67,6 & 23,9 & 35,3 \\
$\mathbf{5 7}$ & 8,24 & 18,7 & 53,4 & 64,8 & 22,7 & 35 \\
$\mathbf{5 8}$ & 7,68 & 17,7 & 52,2 & 68 & 23,1 & 34 \\
$\mathbf{5 9}$ & 6,77 & 16 & 46,6 & 68,9 & 23,7 & 34,4 \\
$\mathbf{6 0}$ & 7,7 & 17,2 & 50,4 & 65,4 & 22,4 & 34,2 \\
$\mathbf{6 1}$ & 8,9 & 18,6 & 53 & 60 & 21 & 35 \\
$\mathbf{6 2}$ & 7,65 & 16,9 & 49,6 & 64,9 & 22 & 34 \\
$\mathbf{6 3}$ & 8,5 & 19 & 56 & 65 & 22 & 34 \\
$\mathbf{6 4}$ & 7,7 & 16,4 & 48 & 62 & 21 & 34 \\
$\mathbf{6 5}$ & 9,5 & 21,6 & 61 & 64 & 23 & 35 \\
$\mathbf{6 6}$ & 8,9 & 20 & 56 & 63 & 22 & 36 \\
$\mathbf{6 7}$ & 8,95 & 20,5 & 57,4 & 64,2 & 23 & 25,7 \\
$\mathbf{6 8}$ & 8,23 & 18,4 & 49,9 & 60,6 & 22,3 & 36,8 \\
$\mathbf{6 9}$ & 9,5 & 21,6 & 61 & 64 & 23 & 35 \\
\hline & & & & & & \\
\hline
\end{tabular}


APÊNDICE D - Leucograma (Leucócitos, neutrófilos, metamielócitos, bastonetes e segmentados) de 69 cães adultos e sadios da raça Dachshund - São Paulo/2017

\begin{tabular}{cccccc}
\hline Número & Leucócitos/mm & Neutrófilos & Metamielócitos & Bastonetes & Segmentados \\
\hline $\mathbf{1}$ & 14990 & 12350 & 0 & 0 & 12350 \\
$\mathbf{2}$ & 13800 & 10960 & 0 & 0 & 10960 \\
$\mathbf{3}$ & 8800 & 6270 & 0 & 0 & 6270 \\
$\mathbf{4}$ & 14090 & 11670 & 0 & 0 & 11670 \\
$\mathbf{5}$ & 8080 & 6160 & 0 & 0 & 6160 \\
$\mathbf{6}$ & 5630 & 3170 & 0 & 0 & 3170 \\
$\mathbf{7}$ & 6700 & 2814 & 0 & 0 & 2814 \\
$\mathbf{8}$ & 9600 & 6220 & 0 & 0 & 6220 \\
$\mathbf{9}$ & 11840 & 8380 & 0 & 0 & 8380 \\
$\mathbf{1 0}$ & 9870 & 7380 & 0 & 0 & 7380 \\
$\mathbf{1 1}$ & 9630 & 5750 & 0 & 0 & 5750 \\
$\mathbf{1 2}$ & 10900 & 6867 & 0 & 0 & 6867 \\
$\mathbf{1 3}$ & 7600 & 4940 & 0 & 0 & 4940 \\
$\mathbf{1 4}$ & 6200 & 4154 & 0 & 0 & 4154 \\
$\mathbf{1 5}$ & 5100 & 3876 & 0 & 0 & 3876 \\
$\mathbf{1 6}$ & 5500 & 3344 & 0 & 0 & 3344 \\
$\mathbf{1 7}$ & 8900 & 7209 & 0 & 0 & 7209 \\
$\mathbf{1 8}$ & 4300 & 2881 & 0 & 0 & 2881 \\
$\mathbf{1 9}$ & 9700 & 7760 & 0 & 0 & 7760 \\
$\mathbf{2 0}$ & 9200 & 7452 & 0 & 0 & 7452 \\
$\mathbf{2 1}$ & 7900 & 5451 & 0 & 0 & 5451 \\
$\mathbf{2 2}$ & 8600 & 6278 & 0 & 0 & 6278 \\
$\mathbf{2 3}$ & 6300 & 3780 & 0 & 0 & 3780 \\
$\mathbf{2 4}$ & 8800 & 5632 & 0 & 0 & 5632 \\
$\mathbf{2 5}$ & 8500 & 5950 & 0 & 0 & 5950 \\
$\mathbf{2 6}$ & 10500 & 8295 & 0 & 0 & 8295 \\
$\mathbf{2 7}$ & 8700 & 4611 & 0 & 0 & 4611 \\
$\mathbf{2 8}$ & 10120 & 7670 & 0 & 0 & 7670 \\
$\mathbf{2 9}$ & 7600 & 5624 & 0 & 0 & 5624 \\
$\mathbf{3 0}$ & 8970 & 5000 & 0 & 0 & 5000 \\
$\mathbf{3 1}$ & 9390 & 5700 & 0 & 0 & 5700 \\
$\mathbf{3 2}$ & 10900 & 6870 & 0 & 0 & 6870 \\
$\mathbf{3 3}$ & 8810 & 5910 & 0 & 0 & 5910 \\
$\mathbf{3 4}$ & 13970 & 11020 & 0 & 0 & 11020 \\
$\mathbf{3 5}$ & 8270 & 6080 & 0 & 0 & 6080 \\
$\mathbf{3 6}$ & 7200 & 4752 & 0 & 0 & 4752 \\
$\mathbf{3 7}$ & 6820 & 5160 & 0 & 0 & 5160 \\
$\mathbf{3 8}$ & 8290 & 5320 & 0 & 0 & 5320 \\
$\mathbf{3 9}$ & 10100 & 7070 & 0 & 0 & 7070 \\
$\mathbf{4 0}$ & 9950 & 7360 & 0 & 0 & 7360 \\
\hline & & & & & \\
\hline & & 0 & 0 & 0 & 0 \\
\hline
\end{tabular}




\begin{tabular}{|c|c|c|c|c|c|}
\hline 41 & 4380 & 3100 & 0 & 0 & 3100 \\
\hline 42 & 6700 & 4757 & 0 & 0 & 4757 \\
\hline 43 & 8800 & 5456 & 0 & 0 & 5456 \\
\hline 44 & 6800 & 4964 & 0 & 0 & 4964 \\
\hline 45 & 12140 & 9100 & 0 & 0 & 9100 \\
\hline 46 & 12800 & 9984 & 0 & 0 & 9984 \\
\hline 47 & 8900 & 6052 & 0 & 0 & 6052 \\
\hline 48 & 10200 & 7752 & 0 & 0 & 7752 \\
\hline 49 & 15450 & 9590 & 0 & 0 & 9590 \\
\hline 50 & 8000 & 4880 & 0 & 0 & 4880 \\
\hline 51 & 8300 & 5146 & 0 & 0 & 5146 \\
\hline 52 & 8600 & 6450 & 0 & 0 & 6450 \\
\hline 53 & 13330 & 10670 & 0 & 0 & 10670 \\
\hline 54 & 8430 & 5270 & 0 & 0 & 5270 \\
\hline 55 & 6670 & 4550 & 0 & 0 & 4550 \\
\hline 56 & 10290 & 6120 & 0 & 0 & 6120 \\
\hline 57 & 8360 & 5350 & 0 & 0 & 5350 \\
\hline 58 & 11220 & 7200 & 0 & 0 & 7200 \\
\hline 59 & 7980 & 4790 & 0 & 0 & 4790 \\
\hline 60 & 10940 & 8490 & 0 & 0 & 8490 \\
\hline 61 & 9800 & 7644 & 0 & 0 & 7644 \\
\hline 62 & 8620 & 6430 & 0 & 0 & 6430 \\
\hline 63 & 8500 & 6545 & 0 & 0 & 6545 \\
\hline 64 & 7800 & 5772 & 0 & 0 & 5772 \\
\hline 65 & 10500 & 8085 & 0 & 0 & 8085 \\
\hline 66 & 6300 & 9954 & 0 & 0 & 9954 \\
\hline 67 & 11050 & 8480 & 0 & 0 & 8480 \\
\hline 68 & 6800 & 4470 & 0 & 0 & 4470 \\
\hline 69 & 10940 & 8490 & 0 & 0 & 8490 \\
\hline
\end{tabular}


APÊNDICE E - Leucograma (Linfócitos tipicos, linfócitos atípicos, monócitos, eosinófilos e basófilos) de 69 cães adultos e sadios da raça Dachshund - São Paulo/2017

\begin{tabular}{cccccc}
\hline Número & $\begin{array}{c}\text { Linfócitos } \\
\text { Típicos }\end{array}$ & $\begin{array}{c}\text { Linfócitos } \\
\text { Atípicos }\end{array}$ & Monócitos & Eosinófilos & Basófilos \\
\hline $\mathbf{1}$ & 1470 & 0 & 880 & 210 & 80 \\
$\mathbf{2}$ & 1530 & 0 & 830 & 390 & 100 \\
$\mathbf{3}$ & 1610 & 0 & 610 & 280 & 20 \\
$\mathbf{4}$ & 1420 & 0 & 770 & 190 & 40 \\
$\mathbf{5}$ & 1290 & 0 & 300 & 320 & 0 \\
$\mathbf{6}$ & 1740 & 0 & 220 & 470 & 30 \\
$\mathbf{7}$ & 2479 & 0 & 469 & 938 & 0 \\
$\mathbf{8}$ & 2800 & 0 & 380 & 90 & 100 \\
$\mathbf{9}$ & 2580 & 0 & 580 & 250 & 60 \\
$\mathbf{1 0}$ & 1580 & 0 & 430 & 340 & 130 \\
$\mathbf{1 1}$ & 2720 & 0 & 760 & 310 & 90 \\
$\mathbf{1 2}$ & 2398 & 0 & 545 & 1090 & 0 \\
$\mathbf{1 3}$ & 1900 & 0 & 380 & 380 & 0 \\
$\mathbf{1 4}$ & 1178 & 0 & 248 & 620 & 0 \\
$\mathbf{1 5}$ & 867 & 0 & 306 & 51 & 0 \\
$\mathbf{1 6}$ & 1617 & 0 & 198 & 319 & 22 \\
$\mathbf{1 7}$ & 890 & 0 & 178 & 623 & 0 \\
$\mathbf{1 8}$ & 989 & 0 & 258 & 172 & 0 \\
$\mathbf{1 9}$ & 1164 & 0 & 485 & 291 & 0 \\
$\mathbf{2 0}$ & 1104 & 0 & 460 & 184 & 0 \\
$\mathbf{2 1}$ & 1738 & 0 & 632 & 79 & 0 \\
$\mathbf{2 2}$ & 1892 & 0 & 344 & 86 & 0 \\
$\mathbf{2 3}$ & 1953 & 0 & 189 & 378 & 0 \\
$\mathbf{2 4}$ & 2288 & 0 & 528 & 352 & 0 \\
$\mathbf{2 5}$ & 2040 & 0 & 255 & 255 & 0 \\
$\mathbf{2 6}$ & 1365 & 0 & 525 & 315 & 0 \\
$\mathbf{2 7}$ & 2262 & 0 & 348 & 1392 & 87 \\
$\mathbf{2 8}$ & 1320 & 0 & 560 & 560 & 20 \\
$\mathbf{2 9}$ & 1292 & 0 & 228 & 456 & 0 \\
$\mathbf{3 0}$ & 3230 & 0 & 360 & 250 & 130 \\
$\mathbf{3 1}$ & 2810 & 0 & 500 & 370 & 10 \\
$\mathbf{3 2}$ & 2900 & 0 & 500 & 580 & 70 \\
$\mathbf{3 3}$ & 2080 & 0 & 340 & 430 & 50 \\
$\mathbf{3 4}$ & 1970 & 0 & 630 & 250 & 80 \\
$\mathbf{3 5}$ & 1660 & 0 & 380 & 90 & 60 \\
$\mathbf{3 6}$ & 1728 & 0 & 288 & 432 & 0 \\
$\mathbf{3 7}$ & 1120 & 0 & 290 & 150 & 90 \\
$\mathbf{3 8}$ & 2360 & 0 & 390 & 220 & 0 \\
\hline & & & & & \\
& & & & & \\
\hline
\end{tabular}




\begin{tabular}{|c|c|c|c|c|c|}
\hline 39 & 2323 & 0 & 404 & 303 & 0 \\
\hline 40 & 1380 & 0 & 500 & 660 & 40 \\
\hline 41 & 970 & 0 & 270 & 30 & 10 \\
\hline 42 & 1407 & 0 & 268 & 268 & 0 \\
\hline 43 & 2200 & 0 & 1056 & 88 & 0 \\
\hline 44 & 1428 & 0 & 204 & 204 & 0 \\
\hline 45 & 2040 & 0 & 760 & 190 & 40 \\
\hline 46 & 1920 & 0 & 640 & 256 & 0 \\
\hline 47 & 2225 & 0 & 534 & 89 & 0 \\
\hline 48 & 1326 & 0 & 510 & 612 & 0 \\
\hline 49 & 2790 & 0 & 470 & 2510 & 80 \\
\hline 50 & 2240 & 0 & 640 & 240 & 0 \\
\hline 51 & 2573 & 0 & 249 & 332 & 0 \\
\hline 52 & 1376 & 0 & 344 & 430 & 0 \\
\hline 53 & 1310 & 0 & 1180 & 100 & 70 \\
\hline 54 & 2510 & 0 & 430 & 170 & 50 \\
\hline 55 & 1350 & 0 & 460 & 250 & 60 \\
\hline 56 & 2960 & 0 & 670 & 480 & 60 \\
\hline 57 & 1730 & 0 & 350 & 760 & 160 \\
\hline 58 & 3270 & 0 & 390 & 250 & 110 \\
\hline 59 & 2350 & 0 & 350 & 410 & 70 \\
\hline 60 & 1600 & 0 & 750 & 50 & 50 \\
\hline 61 & 980 & 0 & 784 & 392 & 0 \\
\hline 62 & 1580 & 0 & 410 & 140 & 60 \\
\hline 63 & 1275 & 0 & 340 & 340 & 0 \\
\hline 64 & 1638 & 0 & 312 & 78 & 0 \\
\hline 65 & 1575 & 0 & 735 & 105 & 0 \\
\hline 66 & 1953 & 0 & 441 & 63 & 0 \\
\hline 67 & 1570 & 0 & 680 & 270 & 60 \\
\hline 68 & 1860 & 0 & 280 & 150 & 30 \\
\hline 69 & 890 & 0 & 178 & 623 & 0 \\
\hline
\end{tabular}


APÊNDICE F - Contagem plaquetária de 69 cães adultos e sadios da raça Dachshund - São Paulo/2017

\begin{tabular}{|c|c|c|c|}
\hline Número & $\begin{array}{c}\text { Plaquetas } \\
\left(\mathrm{mm}^{3}\right)\end{array}$ & Número & $\begin{array}{c}\text { Plaquetas } \\
\left(\mathrm{mm}^{3}\right)\end{array}$ \\
\hline 1 & 349 & 42 & 340 \\
\hline 2 & 421 & 43 & 262 \\
\hline 4 & 330 & 44 & 230 \\
\hline 5 & 417 & 45 & 254 \\
\hline 6 & 390 & 46 & 372 \\
\hline 7 & 383 & 47 & 280 \\
\hline 8 & 293 & 48 & 207 \\
\hline 9 & 412 & 49 & 432 \\
\hline 10 & 270 & 50 & 310 \\
\hline 11 & 373 & 51 & 330 \\
\hline 12 & 420 & 52 & 403 \\
\hline 13 & 276 & 53 & 280 \\
\hline 14 & 219 & 54 & 275 \\
\hline 15 & 271 & 55 & 324 \\
\hline 16 & 172 & 56 & 140 \\
\hline 17 & 316 & 58 & 370 \\
\hline 18 & 252 & 59 & 445 \\
\hline 19 & 338 & 60 & 307 \\
\hline 20 & 310 & 61 & 380 \\
\hline 21 & 361 & 62 & 321 \\
\hline 22 & 247 & 63 & 336 \\
\hline 23 & 246 & 64 & 498 \\
\hline 24 & 395 & 65 & 358 \\
\hline 25 & 356 & 66 & 308 \\
\hline 26 & 248 & 67 & 263 \\
\hline 27 & 500 & 68 & 128 \\
\hline 28 & 248 & 69 & 336 \\
\hline 29 & 278 & & \\
\hline 30 & 309 & & \\
\hline 31 & 323 & & \\
\hline 32 & 213 & & \\
\hline 33 & 203 & & \\
\hline 34 & 271 & & \\
\hline 35 & 273 & & \\
\hline 36 & 226 & & \\
\hline 37 & 293 & & \\
\hline 38 & 290 & & \\
\hline 39 & 212 & & \\
\hline 40 & 302 & & \\
\hline 41 & 279 & & \\
\hline
\end{tabular}


APÊNDICE G - Função renal e hepática de 69 cães adultos e sadios da raça Dachshund - São Paulo/2017

\begin{tabular}{|c|c|c|c|c|c|c|}
\hline Número & $\begin{array}{l}\text { Ptns } \\
\text { Totais } \\
\text { (g/dL) }\end{array}$ & $\begin{array}{l}\text { Albumina } \\
\text { (g/dL) }\end{array}$ & $\begin{array}{l}\text { ALT } \\
(\mathrm{U} / \mathrm{L})\end{array}$ & $\begin{array}{l}\text { FA } \\
(\mathrm{U} / \mathrm{L})\end{array}$ & $\begin{array}{c}\text { Uréia } \\
\text { (mg/dL) }\end{array}$ & $\begin{array}{c}\text { Creat } \\
\text { (mg/dL) }\end{array}$ \\
\hline 1 & 8,03 & 4,28 & 60,4 & 44,9 & 18,2 & 0,66 \\
\hline 2 & 7,32 & 4,06 & 33,7 & 25,4 & 21,5 & 0,84 \\
\hline 3 & 6,99 & 3,94 & 27,3 & 31,3 & 25,8 & 0,72 \\
\hline 4 & 7,1 & 4,75 & 18,3 & 26,8 & 19,6 & 0,82 \\
\hline 5 & 6,61 & 4,15 & 18,2 & 12,4 & 31,6 & 0,86 \\
\hline 6 & 6,89 & 4,28 & 23,9 & 55,2 & 30,4 & 0,79 \\
\hline 7 & 6,97 & 4,5 & 22,8 & 63,4 & 10,3 & 0,68 \\
\hline 8 & 7,11 & 4,25 & 34,8 & 64,7 & 34,4 & 0,92 \\
\hline 9 & 6,94 & 4,1 & 37,5 & 28,2 & 30,7 & 0,81 \\
\hline 10 & 6,52 & 4,24 & 49,7 & 16,2 & 41 & 0,81 \\
\hline 11 & 6,92 & 3,82 & 46,5 & 17,6 & 71,4 & 0,76 \\
\hline 12 & 8,3 & 4,12 & 22,6 & 11,8 & 30,9 & 1,03 \\
\hline 13 & 6,97 & 4,44 & 25,2 & 15,1 & 24,1 & 0,92 \\
\hline 14 & 6,51 & 3,88 & 13,7 & 10,9 & 58,6 & 0,75 \\
\hline 15 & 6,55 & 3,83 & 21 & 16,7 & 46,9 & 1,07 \\
\hline 16 & 6,93 & 4,27 & 29,6 & 17,2 & 35,1 & 0,9 \\
\hline 17 & 7,89 & 4,53 & 39,2 & 23,6 & 13,5 & 0,73 \\
\hline 18 & 6,42 & 4,29 & 16,6 & 16,6 & 32,8 & 0,77 \\
\hline 19 & 7,5 & 4,56 & 50,1 & 48,9 & 31 & 0,66 \\
\hline 20 & 6,79 & 3,95 & 24,2 & 27,5 & 31,4 & 0,86 \\
\hline 21 & 7,25 & 4,49 & 23,7 & 24 & 37,8 & 0,84 \\
\hline 22 & 7,09 & 4,31 & 20,4 & 24,8 & 31,2 & 0,94 \\
\hline 23 & 6,54 & 4,15 & 18,3 & 19 & 27,6 & 0,82 \\
\hline 24 & 7,22 & 4,56 & 33,6 & 20,2 & 53,2 & 0,84 \\
\hline 25 & 7,29 & 4,47 & 44,9 & 28 & 33,6 & 0,91 \\
\hline 26 & 6,61 & 4,2 & 34,6 & 9,6 & 32,8 & 0,8 \\
\hline 27 & 6,92 & 4,22 & 33 & 10,6 & 26,6 & 0,63 \\
\hline 28 & 7,12 & 4,44 & 29,1 & 13,3 & 38,1 & 1,02 \\
\hline 29 & 6,93 & 4,22 & 14,1 & 26 & 25,8 & 0,87 \\
\hline 30 & 6,1 & 3,92 & 26,9 & 20,5 & 31,5 & 0,83 \\
\hline 31 & 6,92 & 4,3 & 29,6 & 38,4 & 44,7 & 0,98 \\
\hline 32 & 6,37 & 3,69 & 40,5 & 17,2 & 33,2 & 0,73 \\
\hline 33 & 6,25 & 3,78 & 20 & 19,9 & 46 & 1,03 \\
\hline 34 & 7,34 & 4,39 & 32,2 & 29,9 & 18,6 & 0,77 \\
\hline 35 & 6,36 & 4,26 & 19,8 & 30,3 & 37,2 & 0,87 \\
\hline 36 & 6,65 & 4,31 & 19,1 & 10,1 & 34,6 & 0,86 \\
\hline 37 & 6,57 & 4,17 & 53,8 & 13,9 & 48,1 & 0,8 \\
\hline 38 & 7,39 & 4,86 & 31,1 & 23,4 & 41,3 & 0,68 \\
\hline 39 & 6,4 & 3,96 & 22,1 & 12,5 & 33,7 & 0,88 \\
\hline
\end{tabular}




\begin{tabular}{|c|c|c|c|c|c|c|}
\hline 40 & 7,21 & 4,2 & 29,6 & 26,7 & 36,8 & 0,77 \\
\hline 41 & 6,42 & 4,27 & 20,2 & 15,7 & 38,2 & 0,97 \\
\hline 42 & 7,6 & 4,59 & 36,1 & 54,4 & 29,9 & 1,07 \\
\hline 43 & 7,11 & 4,42 & 25,1 & 47,3 & 27,4 & 0,9 \\
\hline 44 & 6,12 & 3,9 & 34,8 & 28,6 & 23 & 0,78 \\
\hline 45 & 6,63 & 3,97 & 19,4 & 13,6 & 43,3 & 0,98 \\
\hline 46 & 7,82 & 4,83 & 38,7 & 24 & 36,3 & 0,74 \\
\hline 47 & 6,98 & 4,29 & 22 & 12,4 & 32,9 & 1,18 \\
\hline 48 & 6,96 & 4,28 & 36,3 & 17,1 & 40 & 0,93 \\
\hline 49 & 6,24 & 3,72 & 31,3 & 71,6 & 32,6 & 0,81 \\
\hline 50 & 7,16 & 4,42 & 59,7 & 27,4 & 36,2 & 0,73 \\
\hline 51 & 6,07 & 4,13 & 18,7 & 9,9 & 37,8 & 0,73 \\
\hline 52 & 6,62 & 4,04 & 25,1 & 24,6 & 40 & 0,67 \\
\hline 53 & 7,28 & 4,45 & 46,8 & 18,6 & 36,8 & 0,83 \\
\hline 54 & 6,45 & 4,05 & 26,3 & 8,1 & 35,9 & 0,73 \\
\hline 55 & 6,68 & 3,89 & 29,9 & 46,7 & 42,8 & 0,73 \\
\hline 56 & 6,73 & 4,16 & 23,9 & 23,3 & 39,2 & 0,81 \\
\hline 57 & 6,25 & 4,04 & 26,6 & 25,3 & 36,6 & 0,72 \\
\hline 58 & 6,03 & 3,7 & 68,4 & 69,8 & 42,6 & 0,7 \\
\hline 59 & 6,26 & 3,8 & 32,2 & 4,1 & 51,5 & 1,01 \\
\hline 60 & 6,45 & 3,94 & 15,1 & 16,2 & 50,1 & 0,76 \\
\hline 61 & 7,69 & 4,26 & 25,9 & 19,1 & 19,2 & 0,62 \\
\hline 62 & 6,85 & 4,29 & 15,2 & 61,5 & 37,6 & 0,94 \\
\hline 63 & 6,96 & 4,55 & 25,4 & 11,9 & 51,7 & 0,76 \\
\hline 64 & 6,8 & 4,13 & 22,8 & 22,6 & 34 & 0,59 \\
\hline 65 & 7,69 & 4,39 & 30,8 & 16,5 & 31,6 & 0,83 \\
\hline 66 & 6,54 & 4,1 & 37,3 & 12,1 & 22,1 & 0,8 \\
\hline 67 & 6,54 & 3,95 & 32,5 & 11,8 & 27,1 & 0,87 \\
\hline 68 & 5,94 & 3,79 & 22 & 22,3 & 28,1 & 0,94 \\
\hline 69 & 7,28 & 4,45 & 46,8 & 18,6 & 36,8 & 0,83 \\
\hline
\end{tabular}

